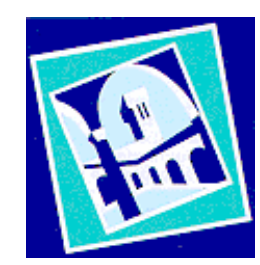

EUROPEAN UNIVERSITY INSTITUTE

DEPARTMENT OF ECONOMICS

EUI Working Paper ECO No. 2005 / 3

Endogenous Globalization and Income Divergence

YOSHAKI SUGIMOTO

BADIA FIESOLANA, SAN DOMENICO (FI) 
All rights reserved.

No part of this paper may be reproduced in any form

Without permission of the author(s).

(C)2005 Yoshiaki Sugimoto

Published in Italy in March 2005

European University Institute

Badia Fiesolana

I-50016 San Domenico (FI)

Italy 


\title{
Endogenous Globalization and Income Divergence
}

\author{
Yoshiaki Sugimoto*
}

March 7, 2005

\begin{abstract}
This paper develops a growth theory that accounts for the evolution of trade policy, underlying internal class conflicts, and global income divergence over the last few centuries. By analyzing political responses to the distributional effects of international trade, this paper finds a prominent interaction between trade policy and the pattern of economic development, and suggests that the nature of the interaction depends on a country's resource abundance and distribution. As shown by the example of Western Europe, land-scarce countries will reach a developed stage through a non-monotonic evolution of trade policy. In contrast, land-abundant countries, especially those with concentrated landownership, tend to fail to take off because of landlords' opposition to industrialization.
\end{abstract}

Keywords: Trade Policy, Growth, Class Conflict.

JEL Classification: F10, F13, F43, O11, O40.

${ }^{*}$ Department of Economics, European University Institute, Via della Piazzuola 43, 50133 Florence, Italy. Email: yoshiaki.sugimoto@iue.it I am grateful to Oded Galor, Wolfgang Keller, Pravin Krishna, Omar Licandro, and seminar participants at Brown University and the EUI for useful comments and encouragement. In addition, I wish to thank Daniel Mejia and Jeffrey G. Williamson for data support. 


\section{Introduction}

Over the last two centuries, he world economy has witnessed two epochal phenomena never seen before: the rapid expansion of international trade and income gaps across nations. The approximate growth rate of intercontinental trade was 3.5 percent per annum in this period, while the figure was 1.1 percent per annum between 1500 and 1800 (O'Rourke and Williamson 2001, Table 1). The gap between the West and the rest of the world in average per capita GDP was nearly 2:1 in 1820, whereas it was as much as 7:1 in 1998 (Maddison 2001, Table 1-9b, 46).

While these figures have brought a potential link between international trade and long-run growth performance to many economists' attention, there seems to be no established theory to account for their historical relationship. As pointed out by Williamson (2003), the role of international trade has typically been neglected by a recent literature analyzing the transition from Malthusian stagnation to modern growth. ${ }^{1}$ Even the few exceptions, such as McDermott (2002) and Galor and Mountford (2003), treat the emergence of international trade as exogenously given. ${ }^{2}$ On the other hand, the literature on endogenous tariff theory primarily builds on static frameworks, silent to the dynamic aspects of trade and aggregate output. ${ }^{3}$

This research distinguishes itself from these previous articles by exploring the historical evolution of trade policy and economic development. Analyzing political response to the distributional effects of trade, the research finds a prominent interaction between these two factors, and emphasizes the role of international trade in income divergence across countries.

The analysis is focused on the development of Western Europe since the 18th century, consisting of four distinct epochs of trade policy. ${ }^{4}$ In the first epoch (1700-1830s), Western European

\footnotetext{
${ }^{1}$ See, for example, Goodfriend and McDermott (1995), Galor and Weil (2000), Kogel and Prskawetz (2001) and Hansen and Prescott (2002).

${ }^{2}$ There are two other notable articles relevant to the present paper. McDermott (1999) endogenizes a country's openness by introducing the government's motivation for mercantilistic protection against the inflow of foreign ideas. In contrast to the present article, he does not study international trade in commodities and hence overlooks the substantial impact of grain inflow on the 19th-century European economy. Baldwin et al. (2001) develop a growth model in which exogenous improvements in various costs of trading goods (such as shipping costs and political barriers) promote industrial agglomeration in the North and thereby provoke great income divergence between the North and South.

${ }^{3}$ See Mayer (1984), Magee, Brock and Young (1989), and Grossman and Helpman (1994), among others.

${ }^{4}$ International trade is considered as between Western Europe and the rest of the world, including Eastern Europe. In the seventeenth and eighteenth centuries, Amsterdam played a central role in determining the grain prices in Europe (Glamann 1974, 457). In the course of the 18th century England and France shifted from intra-European trade to intercontinental trade (Kriedte 1983, Chap. 3), and the late 18th century was the time when the Atlantic trade became the engine of European economic growth (ibid., 125). For example, Carolina's rice exports enlarged five-hold between 1720 and 1740 (Nash 1992, 687).
} 
countries imposed severe restrictions on the import of grain, one of the main foodstuffs, thereby adversely affecting most people's living standards. The second epoch (1830s-1870s) was marked by a decisive shift towards free trade. The resulting influx of grain, especially from the New World, had substantial impacts on income distribution within societies. In response to the grain invasion, many of these nations went back to the protection of domestic agriculture, a competing sector. This political backlash characterizes the third epoch, which has continued until today. On top of these three historical stages, the theory predicts the second wave of globalization in the fourth and final stage. Thus, the evolution of trade policy generally encompasses two surges of liberalism with a stage of protectionism in between.

This paper accomplishes two intriguing objectives. The first and main objective is to analyze the non-monotonic evolution of trade policy experienced by Western Europe, a region plausibly regarded to be scarce in land and abundant in capital. ${ }^{5}$ This non-monotonicity reflects qualitative changes in individuals' preferences towards trade liberalization, and their attitudes vary with the degree of economic development. The present paper provides an interest-based explanation for the determination of openness through an internal political process, rather than political games between trading countries. The second objective is to identify one of the prime sources of global income divergence. ${ }^{6}$

The theoretical model constructed later describes a two-sector, two-good, overlapping-generations economy incorporating two specific factors: land and physical capital, and one mobile factor: human capital. ${ }^{7}$ Three key elements are featured in this model. The first is the absolute importance of food for people in poverty. To be more precise, for the sake of survival people need to spend their incomes exclusively on food up to a certain consumption level. This consumer behavior can

\footnotetext{
${ }^{5}$ According to a careful investigation by Rogowski (1989, pp. 154-158), as late as 1600 Northwestern Europe was abundant in capital and scarce in land, whereas Eastern Europe was abundant in land and scarce in capital. During the 16th century the vast granaries of eastern Germany and Poland had achieved rapid growth, and by the first half of the 17th centuy an annual average of 140,000 tons of grain flowed into Western Europe through the Danish Sound (De Vries 1976, 33). Although England was a net exporter of many grains in the first half of the 18th century, this fact was largely because of the bounty and thus was called "a forced export" (Ormrod 2003, 216-217).

${ }^{6}$ The interest-based approach is taken by Rogowski (1989), who applies the Stolper-Samuelson theorem to interpret class and rural/urban conflicts over trade policies within 19th-century European nations. However, he neither constructs a formal model nor discusses the determination of trade policy. The present article goes beyond these two points in order to analyze the dynamic interaction between trade policy and economic development, with class conflicts being by-products of this interaction.

${ }^{7}$ While the model is an extension of Galor and Moav's (2004) one-sector, one-good growth model, their research accomplishes a saliently different objective: They examine the effects of (exogenous) distributional policies on output growth in a closed economy, and find that the qualitative effects depend on the stage of development.
} 
be viewed as an extreme case of Engel's law. The second element is diversified holdings of production factors. As in Mayer (1984), voting is conducted by individuals who invest in several factors, although human capital is not incorporated into his model. A shift in portfolio composition in the growth process alters individual trade policy preferences. The last element is credit-market imperfection, which leads to borrowing constraints facing agents who invest in a broad range of skills. ${ }^{8}$ Credit-constrained individuals will profitably invest all resources in education, in the presence of the decreasing (constant) returns to scale with respect to investment in human (physical) capital. Hence in underdeveloped stages, wage income, not capital revenues, is the major income source for all but the very rich.

The theory predicts the following scenario for the evolution of a land-scarce, capital-abundant economy. In the early stages of development, the economy operates in a closed system where per capita output of the agricultural product remains constant. Because of the scarcity of land and the necessity for food, the agricultural sector absorbs a substantial amount of labor, depressing the wage in terms of food. The landless poor are thus obliged to devote their entire incomes to food consumption and cannot afford to invest in skill-acquisition. This binding subsistence constraint in autarky sustains landlords' economic dominance at the expense of the rest's poverty. In contrast, engaging in international trade would break down this class structure by placing egalitarian pressure on income distribution: On the one hand, it would raise the wage in terms of food through labor outflows from agriculture, mitigating the cost of living for low-income classes. On the other hand, free trade would reduce real rents and thus landlords' incomes. These two egalitarian forces of globalization - the rise of the working class and fall of the landed elite - are a prime incentive for landlords to prefer autarky. This implies that the initial development process entails a political struggle between the landed and landless classes. Provided that the wealthy class wields political power, the economy adopts protectionist policies reflecting the landlords' position.

While free trade enhances landlords' revenues accrued from industrial capital, this positive effect is not dominant in early stages where industrial capital is a minor asset in their portfolios. However, the accumulation of industrial capital, in conjunction with a limited supply of land, gradually

\footnotetext{
${ }^{8}$ The credit market imperfection approach has been extensively taken by recent theoretical articles examining the effects of income distribution on economic growth. They include Banerjee and Newman (1993), Galor and Zeira (1993), and Benabou (1996). Perotti (1996) and Flug et al. (1998) find empirical support for the significance of the credit-market imperfection as a barrier to educational attainment.
} 
shifts the portfolio composition to capital and thereby makes specialization in manufacturing more profitable for landlords. Accordingly, landlords come to vote for free trade and the economy opens up to international trade. Note that this epochal regime switch dissolves the class conflict in trade policy due to the cost-of-living effect mentioned earlier.

As the economy develops under free trade, further specialization in manufacturing raises the agricultural wage, easing the subsistence constraint binding the working class. This improvement in living standards changes the behavior of landless workers fundamentally in two respects. First, now that they consume the manufactured good as well as food, the wage in terms of the manufactured good becomes an important element in their real wage. Second, they begin to invest in skillacquisition, pushing their incomes further above the subsistence level of food consumption. In these circumstances people in the working class may become less supportive of pro-global (i.e. proindustrial and anti-agricultural) policies since specialization in manufacturing leads to a lower capital-labor ratio in industry and hence to a lower wage in terms of the manufactured good. It should be stressed that the magnitude of their opposition to liberalization largely hinges on the amount of agricultural land. Consistent with the historical evidence given below, protection of agriculture will be intense in moderately land-scarce countries (e.g., Germany and France), where the negative effect of free trade on workers - the decline in the industrial wage - is dominant. Hence, noting that the rise in the middle class income will lead to the extension of the franchise, their political participation results in the resurgence of protectionism. By contrast, the retreat into protectionism does not take place in severely land-scarce countries (e.g., the United Kingdom).

Unless the political backlash is overwhelming, the accumulation of physical and human capital continues to boost output and real wages. The growing economy ultimately reaches highly developed stages where the credit constraint dissipates and members of the landless class invest in education as well as in industrial capital. These newly emerging capitalists form a major interest group in society and support pro-global policies. This is because agricultural land has little value in highly industrialized stages and hence maximizing aggregate output, which occurs under free trade, coincides with maximizing the real wage for the landless class. This result should be interpreted as a prediction of trade policy in unreached, highly developed stages, given the fact that most currently developed countries still adhere to agricultural protection.

The second part of this article demonstrates that the size of landownership is a prime determi- 
nant of development patterns, and hence of global income divergence as well. Large-scale landlords, for whom land rents are the most important income source, have a strong incentive to protect agriculture and substantial amounts of capital are required for them to turn to pro-industrial, liberal policies. Therefore, a country that has abundant land and a small number of landowners is likely to remain protectionist.

It is worthwhile discussing several empirical aspects of the specification of the above model. The model can be viewed as a ramification of the Heckscher-Ohlin model, in the sense that it enables us to explore the effects of relative commodity price on factor prices. Although many empirical papers using the postwar data report the poor performance of the Heckscher-Ohlin model (e.g. Leontief 1953 and Trefler 1995), O'Rourke et al. (1996) confirm its better performance in the late 19th century. Their results indicate that the factor-price convergence between the Old and New Worlds in this period was driven by commodity-price convergence, supporting the factor-price-equalization theorem.

The rest of this chapter is organized as follows. Section 2 offers supporting evidence for European trade policy and economic development. Section 3 outlines the basic structure of the model and Section 4 derives a short-run equilibrium. Section 5 analyzes individuals' trade-policy preferences, which hinge on their wealth levels. Section 6 demonstrates the endogenous evolution of trade policy and aggregate output experienced by industrial economies. Section 7 investigates the role of international trade in income divergence across countries, and Section 8 concludes the discussion. Some proofs of technical results are placed in the Appendix.

\section{Historical Evidence}

This section presents historical evidence of Western European trade policy and economic development, supporting the central argument of the paper. ${ }^{9}$ As mentioned in the introduction, this paper considers both intra-European and intercontinental trade, and the exploration dwells on the role of trade policy, rather than transportation costs, in determining a country's openness. The following four epochs construct a broad picture of the history of Western European trade policy over the last three centuries.

\footnotetext{
${ }^{9}$ I wish to thank Daniel Mejia and Jeffrey G. Williamson for data support for Figure 1 and Figures 2(a)-2(b), respectively.
} 


\subsection{The Age of Protectionism, 1660-1830s}

Protectionism was a prevailing doctrine in Europe during this periods, and the import of grains was forcefully constrained by a series of national laws. The most well-known and important example was the British Corn Laws, which lasted until 1846. ${ }^{10}$ According to Bairoch (1989, 7-8), "It should be noted that 'Corn Laws' were a quasi-permanent feature of tariff history in most European countries. They had always aimed at a precarious balance between protecting local agriculture and preventing the price of bread rising too steeply." For instance, Burke's Act of 1773 fixed the threshold price level on the home market, above which the import of wheat was allowed with customs duties, at 44 shillings per quarter, later raised to 80 shillings by the law of 1815 (ibid., 8). ${ }^{11}$ In France, landowners succeeded in introducing a sliding scale tariff to protect cereals between 1815 and 1845 (Fohlen 1973, 30). Prior to the 19th century protectionist policies against foreign grains were generally binding intra-European trade, rather than intercontinental trade. ${ }^{12}$

The absence of grain imports kept European economies under agricultural-land constraints. Using British data between 1565-1936, O'Rourke and Williamson (2000) find a clear association between commodity and factor prices and endowments for the pre-1828 periods, but note a breakdown in this relationship after 1828 rather than after the 1490s, the era of the Voyages of Discovery. Based on this finding they suggest the superiority of the closed model over the open-economy model before 1828, and the latter's superiority to the former after 1828 .

Working class living standards did not improve in the first epoch; rather they were deteriorating. For instance, Allen (2001, 427-429) reports that welfare indicators of laborers in many European cities exhibited downward or stationary trends during 1500-1800, remaining at the levels where

\footnotetext{
${ }^{10}$ The term 'Corn' did not merely mean American corn or maize, rather the term meant grains such as wheat, oats, rye, varley, malt, peas, beans and maize (Barnes 1965, 7). Although the Corn Laws existed prior to 1660 , it is after 1660 that the government restricted the import of grain and encouraged the export of it (Barnes 1965,8 and Glamann 1974, 465). Apart from the UK, most European countries were protectionist at latest in the early 19th century (Bairoch 1989, 7). This paper conventionally sets 1660 as the initial period.

${ }^{11} \mathrm{~A}$ quarter of wheat was $217.7 \mathrm{~kg}$. The import of wheat was subject to customs duties.

${ }^{12}$ It appears that intercontinental trade in grains were not a main agenda for pre-19th century policy makers due to enormous freight costs. Some historians such as Irwin (2001) and Taylor (2002) are in favor of the view that it was underdeveloped shipping technology, rather than protective policy, that constrained intercontinental trade between the 16th and 18th centuries. While Europe engaged in trade with other continents such as the New World, Asia and India after the Voyages of Discovery, most traded commodities between 1500-1800 were non-competing luxury goods, which had high values compared with their transport costs: e.g. pepper, other spices, cotton textiles, tea and coffee from Asia, and sugar, tobacco and silver from the Americas (Findlay and O'Rourke 2001, 7-10 and Table 1). Since luxury goods were out of the budget of low-income groups, with respect to living standards intercontinental trade was of little relevance to all Europeans except the elite (Irwin 2001 and Williamson 2002c, 16).
} 
incomes are spent mostly on rents and necessities. Similarly, Hoffmann et al. (2002) find that for the period between 1500 and about 1800, both unskilled labor and luxury goods generally became cheaper relative to staple foods (grains and bread) in major European regions (Table 2 and Figure 1, 331-333), and that grain shares were larger in working class budgets than in upper class budgets in England and Wales, France, and the Netherlands (Table 1, 326-327). ${ }^{13}$ The proposed theory predicts the rise in the relative price of food in autarky - a result consistent with the trend in this epoch. What needs to be emphasized is that sustained mass poverty was a major force that constrained the productive activities of most Europeans.

\subsection{The First Globalization, 1830s-1870s}

The triumph of liberalism was symbolized by Britain's repeal of the Corn Law in $1846 .{ }^{14}$ Williamson (1990, Table 1, 128) estimates that the ad valorem tariff equivalent on grain in Britain fell from about 71 percent to about 22 percent between 1815 and 1845 - a great step towards free trade. By 1850, wheat came into Britain continuously from Australia, Argentina, India, the middle west of America and Canada, and the value of wheat exports from the U.S. multiplied by twenty-fold during 1850-1915 (Woodruff, 1973). ${ }^{15}$ In Germany, Belgium, and France, imports of grain accounted for 3 per cent of domestic production in the years 1862-6, reaching to 20 per cent in 1876-80 (Bairoch $1989,47)$.

Britain's liberal ideas spread over much of the European core, especially after 1860, when Britain and France agreed on a commercial treaty including the most-favored-nation clause (Bairoch 1989, 40 and Minchinton 1973, 100). ${ }^{16}$ The spreading of the ideology of liberalism led to the dismantling

\footnotetext{
${ }^{13}$ In 1688-England and Wales, the bottom $40 \%$ of income groups spent about $35 \%$ of their incomes on bread and other grain, whereas the top $5 \%$ spent only $4.2 \%$ on those goods. In France, rural workers spent $30.8 \%$ of their incomes on bread and other grain in 1763, whereas middle and upper classes spent only $1.7 \%$ on them in 1788 . This implies that the relative price of grain was more important for living standards of poorer people.

${ }^{14}$ The present article conventionally defines the1830s as the initial periods of the first globalization. While the triumph of liberalism was symbolized by Britain's repeal of the Corn Law in 1846, the onset of liberalism dates back to the early 1820s. The progress of British liberalization was gradual but steady through the subsequent tariff reforms. In 1822, the nation reduced the threshold price level mentioned above to 70 shillings per quarter (Bairoch 1989, 9). Customs duties on industiral products and raw materials were reduced as well (ibid., 9).

${ }^{15}$ The increase in the years after the late 19th century is accounted for largely by the improvements in transportation costs and technology of wheat production, rather than by liberal trade policy, as agricultural protection was prevailing during this period in Western Europe.

16 "The most-favoured-nation clause is a formula by which each of the two signatories to a treaty agrees to grant the other any advantage, favour, or privilege with regard to trade or navigation that it granted at the time of signing, or that it would grant in the future, to any other nation" (Bairoch 1989, 38-39). According to Minchinton (1973, $100)$, the abolition of grain duties was conducted by the Zollverein in 1853, by Britain in 1860 , by France and the Netherlands in 1862, by Italy in 1870, and by Belgium in 1871 .
} 
of agricultural protection and the associated inflow of grain on an enormous scale, and consequently brought about two major changes in European economies. The first is improvements in withincountry wealth inequality. O'Rourke and Williamson (2003) report that in Northwestern Europe, the wage-land rent ratio was rising prior to the 19th century and started falling at some point in the century. The second is the specialization in capital-intensive goods, which shifts workers from agricultural to industrial sectors. Britain's agricultural workforce began to decline after 1850, a decline tied both to new technologies and to massive increases in agricultural imports (Pomeranz 2000, 287). These two drastic changes indicate that trade liberalization and accompanying grain inflows caused a structural breakdown, transforming Western Europe from an autarkic to an open economy and releasing it from resource constraints. ${ }^{17}$

Political power was wielded by the landed elite in most European nations during this epoch. For example, Aydelotte $(1967,51)$ reckons that the share of the British aristocracy and gentry in the house of commons was roughly 80 percent in 1846, the year of the Corn Law Repeal. Moreover, as depicted in Figure 1, prior to the 1870s the franchise was limited to a small segment of the population in the European core, except France. Since landlords were the richest class during this period and the restriction of the franchise was based on the income level, the dominance of the landed elite was perhaps the most common political characteristic in Europe. Hence many of the landlords' preferences were reflected in the trade policies adopted, and trade liberalization would not have been achieved without their substantial agreement.

One of the prime forces behind the policy switch to free trade was, as mentioned in the introduction, the rising relative importance of industrial capital in landlords' portfolios. ${ }^{18}$ This hypothesis is consistent with the empirical work by Schonhardt-Bailey (1991), who focuses on the case of Britain in the first half of the 19th century. She documents growing diversification of the asset portfolios of British landowners, and also finds that the Members of Parliament representing constituencies with greater diversification were more likely to vote for free trade. Likewise, Thompson (1994,

\footnotetext{
${ }^{17}$ In 1500 , the number of persons per square mile in western Europe plus the New World was 26.7, and the figure declined to 9.0 by 1800 [Jones $(1981,82)$ and Webb $(1952,18)$ ]. This is a substantial positive impact on European resource constraints, counteracting the rapid population growth between the two periods.

${ }^{18}$ According to O'Rourke's (2000) recent review of British trade policy, economic historians proposed two other major reasons for the Corn Law Repeal. Kindleberger (1975) suggests that economic ideas convinced the voters of the efficiency of free trade. By contrast, Irwin (1989) argues that gradual distrust of the Malthusian and Recardian theories prompted the prime minister Robert Peel to convert to liberalism. This research confines its focus to one of the potential sources of trade liberalization.
} 
Table 1 Import Tariff Levels in 1913 (percentage of value)

\begin{tabular}{lcc}
\hline Country & Manufactures & Wheat \\
\hline Austria-Hungary & 20 & 35 \\
Belgium & 9 & 0 \\
Denmark & - & 0 \\
Finland & 28 & 0 \\
France & 21 & 38 \\
Germany & 13 & 36 \\
Italy & 20 & 40 \\
Netherlands & - & 0 \\
Norway & - & 4 \\
Portugal & - & prohibitive \\
Spain & 34 & 43 \\
Sweden & 25 & 28 \\
Switzerland & 8 & 2 \\
United Kingdom & 0 & 0 \\
Continental Europe & 19 & 25 \\
\hline
\end{tabular}

Source. Bairoch (1989, Table 9, 76 and Table 16, 139).

166) documents the aristocracy's decreasing dependence on agricultural incomes in 19th-century England. ${ }^{19}$

\subsection{Political Backlash, 1870s-}

As shown by Minchinton $(1973,100)$, the retreat from free trade occurred in Italy in 1878, in Germany in 1879, in France in 1881, in Bulgaria in 1883, in Switzerland in 1884, in Rumania in 1886, in Belgium and Sweden in 1887, in Austria-Hungary, Spain, Portugal and Russia in the same decades.

The impact of cheap New World and Russian grain became evident in European markets by the late 1870s and 1880s, as was apparent from the 50 percent decline in real British land rents between 1870 and 1913 (Findlay and O'Rourke 2001, 35). Many countries on the European continent re-

\footnotetext{
${ }^{19}$ An empirical study by Scheve and Slaughter (2001) provides indirect evidence for the view that the real estate ownership affects trade-policy preference. Based on individual-level survey data for the United States in recent years, they confirm that trade barriers were more likely to gain supports from individuals whose home ownerships were in counties where comparative-disadvantage industries were concentrated. Home ownership in their study resembles the ownership of agricultural land in this paper's context.
} 
sponded to this 'grain invasion' by protecting domestic agricultural sectors to a greater extent than industrial sectors. This series of political backlashes are observed in the following time-series and cross-sectional data. The time series data from Figures 2(a)-2(b) illustrate that several geographically large countries, such as Austria-Hungary, France, Germany and Italy, were generally raising tariffs during this epoch, whereas the United Kingdom, a geographically small country, was not. ${ }^{20}$ In fact, the United Kingdom maintained free trade until 1932 (Bairoch 1989, 92). Turning to the cross-sectional data, Table 1 shows that the European continent was on average more protectionist against the import of wheat than that of manufactured goods. At country levels, this tendency applies for Austria-Hungary, France, Germany, Italy, Spain, Sweden and possibly Portugal. The United Kingdom, again in sharp contrast, displays considerable and widespread liberalism. The asymmetry in European political responses was initially pointed out by Kindleberger (1951, 33). He argues that "The response of Germany, France, and Italy to the decline in the world price of wheat was to impose tariffs in an attempt to maintain the relative price of wheat and to protect grain producers," whereas "Like Britain, the Netherlands, and Belgium, Denmark did not impose a tariff on wheat." One plausible conjecture from these time-series and cross-sectional records is that between the 1870s and 1913, core European countries generally became protectionist against foreign trade, and that the protection was more intensive in agriculture than in industry.

One must bear in mind that the resurgence of protectionism was not powerful enough to cause a return to the level of economic isolation prior to the first globalization (Williamson 2002a, 4). As shown in Table 2, despite the pro-agricultural policies, European economies remained net importers of primary products and net exporters of the manufactured goods in the beginning and at the end of this epoch, and the opposite is the case for all the other regions.

Two empirical observations are consistent with this article's view that the retreat into protectionism was provoked in part by growing workers. ${ }^{21}$ First, Figure 1 clearly illustrates that many European nations had a dramatic extension of the franchise towards the end of the 19th century, implying that the middle class was gaining political influence. Second, a study by O'Rourke (1997) quantifies the potential impact of cheap grain and finds that the welfare effects of the grain invasion

\footnotetext{
${ }^{20}$ Between the 1870 s and 1890 s, the average tariff rate increased from 4.4 to 10.1 percent in France, and 3.8 to 9.1 percent in Germany (Blattman et al. 2002, 5).

${ }^{21}$ Since there exist only two income classes in the economy considered below, the term 'workers' includes small-size capitalists, whose major income source is wages.
} 
Yoshaki Sugimoto

Table 2 Values of Net Exports, 1876-80 and 1913

\begin{tabular}{lcccc}
\hline & \multicolumn{2}{c}{$1876-80$} & \multicolumn{2}{c}{1913} \\
Region & Primary Goods & Manufactured Goods & Primary Goods & Manufactured Goods \\
\hline United Kingdom & -1245 & 640 & -1836 & 1150 \\
NW Europe & -960 & 630 & -2830 & 1523 \\
Other Europe & 235 & -120 & 104 & -555 \\
USA and Canada & 270 & -90 & 559 & -157 \\
Oceania & & & 326 & -361 \\
Latin America & $838^{*}$ & $-1250^{*}$ & 936 & -828 \\
Africa & & & 373 & -425 \\
Asia & & & 843 & -786 \\
\hline
\end{tabular}

Sources. Findlay and O'Rourke (2001, Table 4) and originally from Lamartine Yates (1959).

* The average of Oceania, Latin America, Africa and Asia.

on workers vary across some European nations. As the present paper does, he focuses on two opposing effects of free trade on the real wage, which emerge in a standard rural-urban specific-factors model: the decline in the wage in terms of the manufactured good and the rise of the wage in terms of food. By utilizing a CGE model whose parameters are based on empirical data, his analysis finds that the former negative effect outweighed the latter positive effect in France, which had large agricultural sectors, whereas the opposite was true for Britain, which had small agricultural sectors (ibid., 792). Given these two results together, this article asserts that within Western Europe, the difference in agricultural size may account for different political responses to the grain invasion.

The protection in agricultural sectors has remained until today, as evidenced by the 2003 WTO meeting in Mexico. Coppel and Durand (1999, Figure 1, 20) find stationary trends in producer support estimates (PSE) in OECD countries' agricultural sectors between 1986 and 1998. During the period the PSEs remained at about $40 \%$ in the European Union, $20 \%$ in the United States and $60 \%$ in Japan-levels above the ones in Australia and New Zealand (ibid., 6). In contrast, trade liberalization in manufactured goods has been successful. Findlay and O'Rourke (2001, Table 5, 67 ) document the declining trend in average tariffs on manufactured goods for 27 major countries between 1913 and 1998. Intercontinental price gaps between 1950 and 2000 were cut by $76 \%$, out of which no less than $74 \%$ can be attributed to trade liberalization (Lindert and Williamson 2001, Table 1). The reports above suggest that this substantial contribution of trade liberalization comes 
predominantly from manufacturing sectors.

\subsection{Summary}

One lesson from the historical evidence presented so far is that a country's trade policy varies over time in accordance with the stage of economic development. A country may even experience a non-monotonic evolution of trade policy in the growth process, as is evidenced by the political backlash in 19th-century Germany and France. Another lesson is that the opening of an economy to international trade paves the way to modern growth by delinking it from resource constraints. Hence, international trade appears to be one of the key determinants for global income divergence. The following sections explore the mechanism that generates the evolution of trade policy, aggregate output, and individual living standards.

\section{The Model}

Consider a two-sector overlapping-generations economy that operates in a two-good world over infinite discrete time. There are three factors of production: land, physical capital and human capital. An agricultural good is produced in one sector by employing land and human capital, while a manufactured good is produced in the other by using physical and human capital. The accumulation of the two kinds of capital is the engine of economic growth; it occurs through private investment in assets and education, subject to borrowing constraints. The supply of land and the levels of population and technology are constant over time. ${ }^{22}$

The economy may take part in international trade of final goods with no effect on the world market. While the world economy imposes no restriction on trade, the economy described below may become protectionist. The government, through the internal political process, sets up the level of a tariff and thus the domestic prices as the only means of trade protection. Tariff revenues are not rebated to individuals but are spent completely on consumption by the government.

\subsection{Production of Final Goods}

The economy has perfectly competitive markets for both the final goods and the inputs, while households rent the services of land, physical capital and human capital out to producers. Indepen-

\footnotetext{
${ }^{22}$ The inclusion of physical capital in agricultural production would not alter the basic results, as long as the industrial capital accumlation promotes labor migration to the manufacturing sector.
} 
dent of the political decision on trade policies, all agents in the markets act as price takers who can perfectly predict the future course of the economy. Human capital is completely mobile between the sectors and all factors are, unlike final goods, immobile across countries. The supply of human capital depends on the educational investment in the preceding period.

\subsubsection{The Agricultural Sector}

This sector generates the agricultural good, which is perishable and indispensable for survival, in the production process governed by a neoclassical technology. Let $X_{t}$ and $H_{t}^{A}$ denote the quantities of land and human capital employed by this sector at time $t$. The output of the agricultural good produced at time $t, y_{t}^{A}$, is then

$$
y_{t}^{A}=F\left(X_{t}, H_{t}^{A}\right)=\left[a X_{t}^{\rho}+(1-a)\left(H_{t}^{A}\right)^{\rho}\right]^{1 / \rho},
$$

where $a \in(0,1)$ and $\rho \in(-\infty, 0)$. The parameter restriction imposed on $\rho$ generates an upper bound of output when one of their inputs are fixed in supply. ${ }^{23}$ The marginal productivity with respect to each input goes to zero as the input becomes infinitely large, whereas the other Inada conditions are not satisfied: The marginal productivity with respect to each input remains finite as the input approaches zero.

In contrast to individuals facing liquidity constraints, producers are allowed to rent land freely on the grounds that land is easily collateralized compared to human capital. Hence, producers in period $t$ maximize their profits given $p_{t}$, the price of the agricultural good, $\rho_{t}$, the rental price per unit of land, and $w_{t}^{A}$, the wage per unit of human capital in period $t$. The manufactured good is taken as the numeraire. This standard profit-maximization is to maximize $p_{t} y_{t}^{A}-\rho_{t} X_{t}-w_{t}^{A} H_{t}^{A}$ with respect to $X_{t}$ and $H_{t}^{A}$. Substituting a fixed land supply into the resulting inverse demand functions leads to

$$
\begin{aligned}
& \rho_{t}=p_{t} F_{X}\left(X, H_{t}^{A}\right) ; \\
& w_{t}^{A}=p_{t} F_{H}\left(X, H_{t}^{A}\right),
\end{aligned}
$$

where $X>0$ is a fixed supply of land and $F_{i}$ denotes the partial derivative of function $F$ with respect to argument $i\left(F_{H} \equiv \partial F(\cdot) / \partial H_{t}^{A}\right.$ for simplicity $){ }^{24}$

\footnotetext{
${ }^{23}$ As will become apparent, the economy characterized by $\rho=0$ (i.e., the Cobb-Douglas technolocy) would not completely specialize in manufacturing even at developed stages. In this case one could maintain the central argument of the paper at the cost of exposition.

${ }^{24}$ This notation applies to all functions in what follows.
} 


\subsubsection{The Manufacturing Sector}

This sector generates the manufactured good that can be consumed or stored. Let $K_{t}$ and $H_{t}$ be the aggregate quantities of physical and human capital, respectively, employed by the manufacturing sector in period $t$. This sector's total output in period $t, y_{t}^{M}$, is

$$
y_{t}^{M}=M K_{t}^{\alpha}\left(H_{t}^{M}\right)^{1-\alpha}=M k_{t}^{\alpha} H_{t}^{M},
$$

where $\alpha \in(0,1), k_{t} \equiv K_{t} / H_{t}^{M}$, and $M>0$ denotes the level of technology.

As in the agricultural sector, producers in period $t$ maximize their profits given $w_{t}^{M}$, the market wage per unit of human capital, and $r_{t}$, the rental price per unit of physical capital in period $t$. The inverse demand functions are therefore

$$
\begin{aligned}
& r_{t}=\alpha M k_{t}^{\alpha-1} \equiv r\left(k_{t}\right) \\
& w_{t}^{M}=(1-\alpha) M k_{t}^{\alpha} \equiv w\left(k_{t}\right) .
\end{aligned}
$$

The rate of return on human capital, $w_{t}^{M}$, increases with physical capital because of their complementarity in production.

\subsubsection{Aggregate Output}

The aggregate level of human capital at time $t, H_{t}$, is not less than the working population, which is one for all $t$. Since there is no unemployment in the described circumstances,

$$
H_{t}=H_{t}^{A}+H_{t}^{M} \geq 1
$$

The economy's aggregate output in period $t, y_{t}$, is

$$
y_{t} \equiv p_{t} y_{t}^{A}+y_{t}^{M}=p_{t} F\left(X, H_{t}^{A}\right)+M K_{t}^{\alpha}\left(H_{t}-H_{t}^{A}\right)^{1-\alpha}
$$

where $\partial y_{t} / \partial p_{t}=y_{t}^{A}$ and $\partial y_{t} / \partial H_{t}^{A}=w_{t}^{A}-w_{t}^{M}$. Noting the strict concavity of the production functions, it follows that $H_{t}^{A}=\arg \max y_{t}$.

Human capital moves to the sector offering a higher wage, and as long as both sectors are active, the perfect mobility of human capital equalizes $w_{t}^{A}$ and $w_{t}^{M}$. That is,

$$
w\left(k_{t}\right)=p_{t} F_{H}\left(X, H_{t}^{A}\right)
$$


The existence of $F_{H}(X, 0)$ implies that the wage equalization above may not hold depending on the levels of $k_{t}$ and $p_{t}$. Let $p_{t}^{\min }=p^{\min }\left(k_{t}\right)>0$ be the price level such that $w\left(k_{t}\right)=p_{t}^{\min } F_{H}(X, 0)$ for $k_{t}>0$. Then in light of $(7)$,

$$
H_{t}^{A}=H^{A}\left(k_{t}, p_{t}\right) \quad \text { for }\left(k_{t}, p_{t}\right) \gg 0,
$$

where $H^{A}(\cdot)=0$ for $p_{t} \leq p_{t}^{\min }$, and $H^{A}(\cdot)>0$ with $H_{k}^{A}(\cdot)<0$ and $H_{p}^{A}(\cdot)>0$ for $p_{t}>p_{t}^{\min }$. Moreover, $\lim _{k_{t} \rightarrow 0} H^{A}(\cdot)=H_{t}$ and $\lim _{k_{t} \rightarrow \infty} H^{A}(\cdot)=0$.

\subsection{Individuals}

\subsubsection{Environment}

A new generation, consisting of a continuum of individuals, is born in the beginning of every period and lives over the course of two periods. Hence there are two generations in society at each point in time. The size of population is normalized to one. Individuals may differ in their endowments, yet they are homogeneous in all the other aspects. An individual born in period $t$ is referred to as a member $i \in[0,1]$ of generation $t$.

In the first period of life (youthhood), a member $i$ of generation $t$ has a single parent and spends the entire time acquiring skills. The formation of human capital is augmented by investing the manufactured good in education during this period. The education costs are financed from the wealth transferred from her parent, $b_{t}^{i} \geq 0$. The amount saved by this individual is thus $s_{t}^{i}=b_{t}^{i}-e_{t}^{i}$.

In the second period (adulthood), the individual has a single child and acquires human capital $h_{t+1}^{i} \equiv h\left(e_{t}^{i}\right)$, where $h(\cdot)$ is an increasing, strictly concave function satisfying the Inada conditions and $h(0)=1$. The last condition implies that no real expenditure on education results in labor with basic skills. By supplying the human capital inelastically, the individual receives the wage income $w_{t+1} h_{t+1}^{i}$, where $w_{t+1}$ is the market wage rate in terms of the manufactured good at time $t+1$. On top of that, those who have savings or landownership respectively receive interest rates or rents from producers. Unlike physical capital, there is no market for landownership: land is under the ownership of old individuals and is inherited by their offsprings after every period. To summarize, the second period's income of a member $i$ of generation $t, I_{t+1}^{i}$, is

$$
I_{t+1}^{i}=w_{t+1} h\left(e_{t}^{i}\right)+R_{t+1}\left(b_{t}^{i}-e_{t}^{i}\right)+\rho_{t+1} x^{i},
$$


where $R_{t+1} \equiv 1+r\left(k_{t+1}\right)-\delta \equiv R\left(k_{t+1}\right)$ and $x^{i}$ denotes the amount of land owned by the individual. In order to simplify the analysis of the dynamical system, the complete capital depreciation, $\delta=1$, is assumed in what follows.

\subsubsection{Consumption}

In this two-good world, the agricultural good is thought of as staple food essential for survival. Suppose that food consumption is absolutely essential for adult individuals. More precisely, they spend their incomes exclusively on the agricultural good up to a certain level, $\hat{c}>0$, and the demand for the agricultural good, which serves merely for survival, saturates at $\hat{c}^{25}$ The food consumption of a member $i$ of generation $t, c_{t+1}^{A, i}$, is therefore

$$
\begin{array}{ll}
c_{t+1}^{A, i}=I_{t+1}^{i} / p_{t+1} & \text { if } I_{t+1}^{i}<p_{t+1} \hat{c} \\
c_{t+1}^{A, i}=\hat{c} & \text { if } I_{t+1}^{i} \geq p_{t+1} \hat{c} .
\end{array}
$$

The remaining income is spent on $c_{t+1}^{M}$, consumption of the manufactured good, and $b_{t+1}$, the manufactured good transferred to her child, so as to maximize the utility function ${ }^{26}$

$$
u_{t}=\left(c_{t+1}^{M}\right)^{1-\beta} b_{t+1}^{\beta}, \quad \text { with } \beta \in(0,1),
$$

subject to $c_{t+1}^{A}=\hat{c}$ and the budget constraint

$$
p_{t+1} c_{t+1}^{A}+c_{t+1}^{M}+b_{t+1} \leq I_{t+1}^{i}
$$

It follows that the optimal transfer of this individual is

$$
b_{t+1}^{i}=\beta\left(I_{t+1}^{i}-p_{t+1} c_{t+1}^{A, i}\right)=\beta \max \left(I_{t+1}^{i}-p_{t+1} \hat{c}, 0\right) .
$$

Let $v_{t}^{i}$ be the indirect utility function of a member $i$ of generation $t$ in the absence of the food constraint (i.e., $\left.I_{t+1}^{i} / p_{t+1}>\hat{c}\right)$. Then,

$$
v_{t}^{i}=\epsilon\left(I_{t+1}^{i}-p_{t+1} \hat{c}\right), \quad \text { with } \epsilon \equiv(1-\beta)^{1-\beta} \beta^{\beta}
$$

\footnotetext{
${ }^{25}$ One may suppose that children consume a part of the food their parents purchase. For the sake of simplicity, it is assumed that no one dies regardless of the amount of food consumption. Incorporating a death rate makes the model more realistic, yet is not essential for this paper's qualitative results.

${ }^{26}$ The qualitative results of the paper would be intact under a more realistic utility function $\left(1-\beta_{1}-\beta_{2}\right) \ln c_{t+1}^{M}+$ $\beta_{1} \ln b_{t+1}+\beta_{2} \ln \left(c_{t+1}^{A}-\hat{c}\right)$, provided that $\beta_{2}$, the weight of excess food consumption, is sufficiently small.
} 


\subsubsection{Investment}

Each individual with perfect foresight invests in education and savings as a price taker. (10) and (14) assert that regardless of the food constraint, the optimal investment is to maximize the second period's income $I_{t+1}^{i}$. Let $e_{t}$ be the desirable level of education in period $t$ for a given $k_{t+1}>0$, in the absence of borrowing constraints. It follows from (36) and (9) that

$$
e_{t}=\underset{e}{\arg \max }\left[w\left(k_{t+1}\right) h(e)-R\left(k_{t+1}\right) e\right]
$$

In view of the assumptions made on $h(\cdot)$, there exists a single-valued function

$$
e_{t}=e\left(k_{t+1}\right)>0 \quad \text { for } k_{t+1}>0
$$

where $e^{\prime}\left(k_{t+1}\right)>0$ with the Inada conditions. ${ }^{27}$ The intuition behind the positive reaction of education to the capital ratio is straightforward: an increase in $k_{t+1}$ raises the return on human capital, $w_{t+1}$, while reducing the return on savings, $R_{t+1}$. In order to simplify the analysis, it is assumed that

$$
e^{\prime \prime}\left(k_{t+1}\right) \leq 0, \quad \forall k_{t+1}>0
$$

This condition depends on the third derivative as well as the first and second derivatives of $h(\cdot)$.

In this economy, imperfections of the capital market eliminate any possibility for individuals to make loans for education. Furthermore, they have no access to international capital markets. Hence, while $e_{t}$ is the first-best choice for all young members at time $t$, those facing the borrowing constraint cannot achieve such a desirable level of education. A member $i$ of generation $t$ accordingly invests in education in a way that ${ }^{28}$

$$
e_{t}^{i}= \begin{cases}e_{t} & \text { if } b_{t}^{i} \geq e_{t} \\ b_{t}^{i} & \text { otherwise }\end{cases}
$$

The amount of savings is now expressed as

$$
s_{t}^{i}=b_{t}^{i}-e_{t}^{i}= \begin{cases}b_{t}^{i}-e_{t} & \text { if } b_{t}^{i} \geq e_{t}, \\ 0 & \text { otherwise. }\end{cases}
$$

\footnotetext{
${ }^{27}$ One of the Inada conditions imposed on $h(\cdot)$ eliminates the case that $e\left(k_{t+1}\right)=0, \exists k_{t+1}>0$. As will become clear, alternative specifications of $h(\cdot)$ would not alter the basic scenarios of the paper but complicate the exposition.

${ }^{28}$ The second case in (17) includes the possibility that $k_{t+1}$ and thus $e_{t}$ do not exist (i.e., $K_{t}=H_{t}^{M}=0$ ). The nonexistence of $k_{t+1}$ means the complete specialization to agriculture in period $t+1$, and thus all resources are optimally used for skill acquisition in period $t$. Note also that $k_{t+1}$ never becomes 0 because no workers engage in the manufacturing sector that produces no output (recall that if $K_{t}=0, y_{t}^{M}=0$ for any $H_{t}^{M} \geq 0$ ).
} 
Taking (17) and (18) into account, the second period's income from (9) is revised to

$$
I_{t+1}^{i}= \begin{cases}w_{t+1} h\left(e_{t}\right)+R_{t+1}\left(b_{t}^{i}-e_{t}\right)+\rho_{t+1} x^{i} & \text { if } b_{t}^{i} \geq e_{t} \\ w_{t+1} h\left(b_{t}^{i}\right)+\rho_{t+1} x^{i} & \text { otherwise }\end{cases}
$$

This result along with (13) suggests that the heterogeneity of $b_{t+1}^{i}$ arises from those of $b_{t}^{i}$ and $x^{i}$.

\subsection{Initial Distribution of Wealth}

In period 0 , there are two income groups in society, $R$ (Rich) and $P$ (Poor), which respectively comprise fixed fractions $\lambda \in(0,1 / 2)$ and $1-\lambda$ of population. The entire amounts of land and capital in the economy are distributed evenly among the old members of group $R$, whereas those of group $P$ are proletarian.

The initial transfers depend on the initial levels and distributions of the three factors for production. Assuming that $K_{0}>0$ and $h_{0}^{R}=h_{0}^{P}=1$, one can get

$$
\begin{aligned}
& b_{0}^{R}=\beta \max \left[w_{0}+\left(\rho_{0} X+R_{0} k_{0}\right) / \lambda-p_{0} \hat{c}, 0\right] \\
& b_{0}^{P}=\beta \max \left(w_{0}-p_{0} \hat{c}, 0\right)
\end{aligned}
$$

where $\rho_{0} X+R_{0} k_{0}>0$. As shown below, the initial ranking of wealth among people does not reverse in the future.

Corollary 1 Given the initial condition (20), $I_{t}^{R}>I_{t}^{P}$ and $b_{t}^{R} \geq b_{t}^{P}$ for all $t \geq 0$, with equality only if $b_{t}^{R}=b_{t}^{P}=0$.

Proof. (20) implies that $I_{0}^{R}>I_{0}^{P}$ and $b_{0}^{R} \geq b_{0}^{P}$ with equality only if $b_{0}^{R}=b_{0}^{P}=0$. Hence the results for period $t \geq 2$ follow from (13) and (19).

\section{Short-Run Equilibrium}

This section considers the determination of aggregate variables and transfers in each period.

\subsection{Aggregate Capital and Output}

In the absence of the opportunity for international lending and borrowing, the aggregate stock of physical capital equals aggregate savings. Since Corollary 1 excludes the case $0<b_{t}^{R} \leq b_{t}^{P}$, (18) 
yields

$$
K_{t+1}=\lambda s_{t}^{R}+(1-\lambda) s_{t}^{P}= \begin{cases}B_{t}-e_{t} & \text { if } e_{t} \leq b_{t}^{P}<b_{t}^{R} \\ B_{t}-\lambda e_{t}-(1-\lambda) b_{t}^{P} & \text { if } b_{t}^{P}<e_{t}<b_{t}^{R} \\ 0 & \text { otherwise, }\end{cases}
$$

where $B_{t} \equiv \lambda b_{t}^{R}+(1-\lambda) b_{t}^{P}$ is the aggregate transfer allocated between investment in physical and that in human capital. Note that group $R$ 's savings are indispensable for the formation of physical capital.

Human capital fully depreciates in one period since workers die off. It thus follows from (17) that the aggregate stock of human capital in period $t+1$ is

$$
H_{t+1}=\lambda h\left(e_{t}^{R}\right)+(1-\lambda) h\left(e_{t}^{P}\right)= \begin{cases}h\left(e_{t}\right) & \text { if } e_{t} \leq b_{t}^{P}<b_{t}^{R} \\ \lambda h\left(e_{t}\right)+(1-\lambda) h\left(b_{t}^{P}\right) & \text { if } b_{t}^{P}<e_{t}<b_{t}^{R} \\ \lambda h\left(b_{t}^{R}\right)+(1-\lambda) h\left(b_{t}^{P}\right) & \text { otherwise. }\end{cases}
$$

It thus follows from (5), (8) and (15) that the industrial capital-labor ratio is

$$
k_{t+1}=\frac{B_{t}-\theta_{t} e_{t}-\left(1-\theta_{t}\right) b_{t}^{P}}{\theta_{t} h\left(e_{t}\right)+\left(1-\theta_{t}\right) h\left(b_{t}^{P}\right)-H^{A}\left(k_{t+1}, p_{t+1}\right)} \equiv q\left(k_{t+1} ; B_{t}, b_{t}^{P}, p_{t+1}, \theta_{t}\right),
$$

where $\theta_{t}$ represents the fraction of young members who are not credit-constrained at time $t .{ }^{29}$ One should note the independence of $q(\cdot)$ from $b_{t}^{P}$ when $\theta_{t}$ is equal to one. The properties of $h(\cdot), e(\cdot)$ and $H^{A}(\cdot)$ ensure that $k_{t+1}=q\left(k_{t+1} ; \cdot\right)$ holds in a perfect-foresight equilibrium. Hence there exists a single-valued function implied by this condition, ${ }^{30}$

$$
k_{t+1}=k\left(B_{t}, b_{t}^{P}, p_{t+1}, \theta_{t}\right)>0
$$

where $^{31}$

$$
\theta_{t}= \begin{cases}1 & \text { if } \quad e(k(\cdot, 1)) \leq b_{t}^{P} \\ \lambda & \text { if } \quad b_{t}^{P}<e(k(\cdot, \lambda))\end{cases}
$$

\footnotetext{
${ }^{29}$ As noted in Footnote 28, if there is no physical capital in period $t+1$, then the physical-human capital ratio $k_{t+1}$ is undefined. The existence of $k_{t+1}$ therefore implies $K_{t+1}>0$; i.e., members of group $R$ are never credit-constrained and always have a positive amount of savings.

${ }^{30}$ The function $k\left(B_{t}, b_{t}^{P}, p_{t+1}, \theta_{t}\right)$ is defined on the set $\mathbb{R}_{++} \times\left[0, B_{t}\right] \times\left(0, p_{t+1}^{\max }\right) \times(0,1]$, where $p_{t+1}^{\max }$ is defined in (67) in the Appendix. Although the function exists for $p_{t+1}>p_{t+1}^{\max }$ as well, the Appendix demonstrates that both $K_{t+1}$ and $H_{t+1}^{M}$ are positive only for the aforementioned price range. In what follows, these four endogenous variables are defined on this set.

${ }^{31} e(k(\cdot, 1))=b_{t}^{P}$ if and only if $e(k(\cdot, \lambda))=b_{t}^{P}$ because $q(\cdot, 1)=q(\cdot, \lambda)$ for a value of $k_{t+1}$ such that $e\left(k_{t+1}\right)=b_{t}^{P}$. Without loss of generality, one can choose $\theta_{t}=1$ if $b_{t}^{P}=e(k(\cdot, 1))=e(k(\cdot, \lambda))$ so that $\theta_{t}$ represents the fraction of members who are not credit-constrained.
} 
Note that

$$
\begin{array}{ll}
\lim _{B_{t} \rightarrow 0} k\left(B_{t}, 0, \cdot\right)=0 ; & \lim _{B_{t} \rightarrow \infty} k(\cdot)=\infty ; \\
k_{B}(\cdot)>0 ; \quad k_{b}(\cdot) \leq 0 ; & k_{p}(\cdot) \geq 0,
\end{array}
$$

where the second inequality holds strictly if and only if $\theta_{t}<1$, and the last inequality holds strictly for $p_{t+1}>p_{t+1}^{\min }$. The economic intuition behind the properties above deserves special emphasis. First, $k_{b}(\cdot)$ is negative when members of group $P$ are credit-constrained (i.e., $\theta_{t}=\lambda$ ), because they invest only in human capital. Second, the positivity of $k_{p}(\cdot)$ reflects the properties of $H^{A}\left(k_{t+1}, p_{t+1}\right)$ in (8); a rise in the relative price of the agricultural good leads to a rise in $w_{t+1}^{A}$, which attracts more workers to the agricultural sector.

Figure 3 visualizes the determination of $\theta_{t}$ on the $\left(B_{t}, b_{t}^{P}\right)$ space for a given price level $p$. The Credit Constraint Frontier, the $C C$ locus, is defined as the set of all pairs $\left(B_{t}, b_{t}^{P}\right)$ for which

$$
b_{t}^{P}=e\left(k\left(B_{t}, b_{t}^{P}, p, 1\right)\right)=e\left(k\left(B_{t}, b_{t}^{P}, p, \lambda\right)\right) .
$$

The frontier converges to zero as $B_{t}$ approaches zero, and its slope is between zero and one. Observe that $e(k(\cdot, 1))<b_{t}^{P}$ on the region above the frontier and $e(k(\cdot, \lambda))>b_{t}^{P}$ on the region below the frontier - both cases are consistent with the definition of $\theta_{t} \cdot{ }^{32}$

The equilibrium level of $k_{t+1}$ is now expressed as a continuous single-valued function

$$
k_{t+1}=\kappa\left(B_{t}, b_{t}^{P}, p_{t+1}\right)
$$

where $p_{t+1} \in\left(0, p_{t+1}^{\max }\right)$. Once the level of $k_{t+1}$ is given, then $K_{t+1}, H_{t+1}$, the labor allocation and the factor prices are all determined by individuals' investment and the competitive market mechanism.

In light of $p_{t}^{\min }$ defined for (8) and the discussion in the Appendix, the patterns of specialization are summarized as

$$
\begin{array}{lllll}
y_{t}^{A}=0 & \text { and } & y_{t}^{M}>0 & \text { if } & p_{t} \in\left(0, p_{t}^{\min }\right], \\
y_{t}^{A}>0 & \text { and } & y_{t}^{M}>0 & \text { if } & p_{t} \in\left(p_{t}^{\min }, p_{t}^{\max }\right), \\
y_{t}^{A}>0 & \text { and } & y_{t}^{M}=0 & \text { if } & p_{t} \in\left[p_{t}^{\max }, \infty\right) .
\end{array}
$$

Substituting (21) and (22) into (6), aggregate output in period $t+1$ is now expressed as

$$
y_{t+1}=y\left(B_{t}, b_{t}^{P}, p_{t+1}\right)=\lambda I_{t+1}^{R}+(1-\lambda) I_{t+1}^{P},
$$

\footnotetext{
${ }^{32}$ By contrast, $e(k(\cdot, \lambda))<b_{t}^{P}$ on the region above the frontier and $e(k(\cdot, 1))>b_{t}^{P}$ on the region below the frontierboth cases are inconsistent with the definition of $\theta_{t}$.
} 
where as follows from (2) and (4),

$$
\begin{aligned}
& y_{B}(\cdot)>0, \\
& y_{b}(\cdot)\left\{\begin{array}{l}
=0 \quad \text { if } \quad p_{t+1} \in\left(0, p_{t+1}^{\max }\right) \text { and } b_{t}^{P} \geq e_{t} ; \\
>0
\end{array}\right. \text { otherwise, } \\
& y_{p}(\cdot)=y_{t+1}^{A},
\end{aligned}
$$

where in particular, $y_{B}(\cdot)=R_{t+1}$ when the manufacturing sector is active. Note that $e_{t}=$ $\arg \max y_{t+1}^{M}$. The last equality in (27) reflects the linear homogeneity of the production functions. The aggregate income is allocated entirely to old members, who are the owners of inputs.

\subsection{The Goods' Markets}

\subsubsection{The Open Economy}

To the extent that the economy is open to the world markets, the domestic demand for each commodity does not need to match the domestic supply, and the gap between them can be filled by either exports or imports. The payment of foreign trade always balances in the domestic economy.

\subsubsection{The Closed Economy}

The domestic demand for and supply of each good are equated when the economy is completely closed to the world markets. In light of Walras' law, one can focus on the agricultural good's market. As follows from (1), (7), (10) and (26), the clearance of the market at time $t$ is achieved by a pair $\left(H_{t}^{A}, p_{t}\right)$ such that

$$
\begin{aligned}
& F\left(X, H_{t}^{A}\right)=\lambda \min \left(I_{t}^{R} / p_{t}, \hat{c}\right)+(1-\lambda) \min \left(I_{t}^{P} / p_{t}, \hat{c}\right) \\
& p_{t}=\frac{w\left(k_{t}\right)}{F_{H}\left(X, H_{t}^{A}\right)} \in\left(p_{t}^{\min }, p_{t}^{\max }\right) \quad \text { iff } H_{t}^{A} \in\left(0, H_{t}\right)
\end{aligned}
$$

There are two assumptions to be made for the economic environment in period 0. First, the economy operates in a closed system where both sectors are active. ${ }^{33}$ The initial operation of industry, which requires landowners who can afford transfers in period 0, ensures the transition

\footnotetext{
${ }^{33}$ This paper deals with only the case in which both sectors are active in autarkic equilibrium. Note that there is a possibility that the autarkic economy does not produce the manufactured good. For example, it follows from (44) below that $y_{0}^{M}=B_{0}=0$ if $H_{0}^{A}=1$ in (29). By contrast, agricultural output is always positive in the closed system, because of the demand function (10) and a positive amount of land.
} 
from an agrarian to industrial economy. Second, the food constraint is strictly binding only for group $P$. This initial inequality between two income classes would be historically plausible and enables us to examine the effect of international trade on people in different living standards.

Recalling that adult members of group $P$ are endowed with nothing but basic skills in period 0 , one can find that $I_{0}^{P} / p_{0}=F_{H}\left(X, H_{0}^{A}\right)$ from (7) and (19). Since they are facing the food constraint, the initial employment level $H_{0}^{A}$ satisfies the first market-clearing condition of (28) in a way that

$$
F\left(X, H_{0}^{A}\right)=\lambda \hat{c}+(1-\lambda) F_{H}\left(X, H_{0}^{A}\right)<\hat{c},
$$

where $H_{0}^{A} \in(0,1)$ is assumed in order to assure that both sectors operate in period $0 .{ }^{34}$

It thus follows from (7) that the autarkic price in period $0, p_{0}$, is

$$
p_{0}=\frac{w\left(k_{0}\right)}{F_{H}\left(X, H_{0}^{A}\right)}, \quad \text { where } k_{0}=\frac{K_{0}}{1-H_{0}^{A}}>0
$$

Since this means $y_{0}^{M}>0,(27)$ and $(29)$ yield

$$
I_{0}^{R} / p_{0}>\left[F\left(X, H_{0}^{A}\right)-(1-\lambda) F_{H}\left(X, H_{0}^{A}\right)\right] / \lambda=\hat{c}
$$

consistent with the second initial condition.

Lemma 1 If (29) is satisfied, then for $t \geq 1$, a pair $B_{t-1}>b_{t-1}^{P}=0$ leads to $I_{t}^{P}=w_{t}<p_{t} \hat{c}<I_{t}^{R}$ and $H_{t}^{A}=H_{0}^{A}$.

Proof. See the Appendix.

Let $p_{t}^{c}$ be the autarkic price at time $t$. Then, substituting $H_{t+1}^{A}=H_{0}^{A}$ into (23) and then using (28) produce $p_{t+1}^{c}=p^{c}\left(B_{t}\right)$ for $B_{t}>0$ and $b_{t}^{P}=0$, where $d p^{c}\left(B_{t}\right) / d B_{t}>0$ and $p^{c}\left(B_{t}\right)<p_{t+1}^{\max }$. It follows that $p_{t+1}^{c}$ satisfies $^{35}$

$$
H^{A}\left(k_{t+1}, p_{t+1}^{c}\right)=H_{0}^{A}, \quad \text { where } k_{t+1}=\kappa\left(B_{t}, 0, p_{t+1}^{c}\right) .
$$

\footnotetext{
${ }^{34}$ The inequality in (29) holds for a sufficiently large $\hat{c}$ since the equality implies that $H_{0}^{A}$ increases with $\hat{c}$. Also, the neoclassical properties of $F(\cdot)$ assure that $H_{0}^{A} \in(0,1)$ is feasible for a sufficiently small $\lambda$. One can find $\lim _{\lambda \rightarrow 0} H_{0}^{A}<1$ by noting that

$$
F(X, 1)>F_{H}(X, 1)=\lim _{\lambda \rightarrow 0}\left[(1-\lambda) F_{H}(X, 1)+\lambda \hat{c}\right] .
$$

More generally, $H_{0}^{A}$ could be larger than one, yet must be smaller than $H_{0}=\lambda h_{0}^{R}+(1-\lambda) h_{0}^{P}$.

${ }^{35}(32)$ is satisfied by a unique price level since $H^{A}\left(\kappa\left(B_{t}, 0, p_{t+1}\right), p_{t+1}\right)$ is strictly increasing in $p_{t+1}$. Note that $\theta_{t}=\lambda$ if $B_{t}>0$ and $b_{t}^{P}=0$.
} 


\section{Individuals' Optimal Trade Policies}

This section investigates the optimal prices from the viewpoint of each individual in society. Suppose that the world economy is in a stationary state at a price level $p^{w}>0$. Then the feasible price interval faced by all people is $p_{t+1} \in\left[\min \left(p^{w}, p_{t+1}^{c}\right), \max \left(p^{w}, p_{t+1}^{c}\right)\right] \equiv \mathbf{p}_{t+1}$, which ensures balanced trade and the clearance of the domestic goods' markets.

It follows from (10)-(14) that the desirable price for a member $i$ of generation $t$, denoted as $p_{t+1}^{i}$, is

$$
p_{t+1}^{i}= \begin{cases}\arg \max \left(I_{t+1}^{i} / p_{t+1}\right) & \text { if } I_{t+1}^{i} / p_{t+1} \leq \hat{c}, \forall p_{t+1} \in \mathbf{p}_{t+1} \\ \arg \max \left(I_{t+1}^{i}-p_{t+1} \hat{c}\right) & \text { otherwise, }\end{cases}
$$

where in view of $(27), I_{t+1}^{i}=I^{i}\left(B_{t}, b_{t}^{P}, p_{t+1}\right)$ and thus $v_{t}^{i}=v^{i}\left(B_{t}, b_{t}^{P}, p_{t+1}\right)$.

In order to understand the discussion below, it is important to note that the effects of trade protection on employment in each sector are, ${ }^{36}$

$$
\frac{\partial H_{t}^{A}}{\partial p_{t}}>0 \text { and } \frac{\partial H_{t}^{M}}{\partial p_{t}}<0
$$

\subsection{The Landless Class}

The optimal trade policy for the landless hinges on the effectiveness of the food and credit constraints, and there are three cases to be considered. First, as long as both constraints are binding $\left(I_{t+1}^{P} \leq p_{t+1} \hat{c}\right.$ and $b_{t}^{P} \leq e_{t}$ for any $\left.p_{t+1} \in \mathbf{p}_{t+1}\right)$, they consume only the agricultural good and aim to maximize the income in terms of the agricultural good, $I_{t+1}^{P} / p_{t+1}=F_{H}\left(X, H_{t+1}^{A}\right)$. Hence they support the policy that promotes the specialization in manufacturing.

Secondly, when only the credit constraint is binding, members of group $P$ consume both goods, and their consumption level of the manufactured good depends on the income in terms of the manufactured good, $I_{t+1}^{P}=w_{t+1} h\left(b_{t}^{P}\right)$. Compared to the first case above, they will be less supportive of industrialization since the labor shift to the manufacturing sector reduces the industrial capital-labor ratio $k_{t+1}$, leading to a lower level of $w_{t+1}$.

Lastly, when neither of the constraints is binding, members of group $P$ receive transfers from their parents and save part of them. While both goods are consumed as in the second case above,

\footnotetext{
${ }^{36}$ The first result follows from $H_{p}^{A}(\cdot)+H_{k}^{A}(\cdot) \kappa_{p}(\cdot)>0$. That is, although trade liberalization has a negative effect on the agricultural employment via a decline in the capital ratio, this indirect effect is outweighed by the direct, negative effect of the price change. The second result is implied by (21) and (24).
} 
the interest rate $R_{t+1}$ becomes an additional factor through which $k_{t+1}$ and hence $p_{t+1}$ affect $I_{t+1}^{P}$. The negative effect of $k_{t+1}$ on $R_{t+1}$ counteracts the positive effect of $k_{t+1}$ on $w_{t+1}$, and thereby induces them to support a pro-industrial tariff policy.

\subsection{The Landed Class}

This subsection considers only early development stages where $B_{t}>b_{t}^{P}=0$ and thus $I_{t+1}^{P}=w_{t+1}$ as implied by (19). Since Lemma 1 has shown that in this situation, the food constraint is not binding for landlords in autarky, one can use the second case of (33) with (27) to obtain

$$
\begin{aligned}
p_{t+1}^{R} & =\arg \max v^{R}\left(B_{t}, 0, p_{t+1}\right) \\
& =\arg \max \left[y_{t+1}-(1-\lambda) w_{t+1}-\lambda p_{t+1} \hat{c}\right]
\end{aligned}
$$

Recall $y_{p}(\cdot)=y_{t+1}^{A}$ in $(27)$, and it follows from (26) that

$$
\frac{\partial w_{t}}{\partial p_{t}}= \begin{cases}0 & \text { for } p_{t} \in\left(0, p_{t}^{\min }\right] \\ \gamma_{t} F_{H}\left(X, H_{t}^{A}\right) & \text { for } p_{t} \in\left(p_{t}^{\min }, p_{t}^{\max }\right) \\ F_{H}\left(X, H_{t}\right) & \text { for } p_{t} \in\left[p_{t}^{\max }, \infty\right)\end{cases}
$$

where $\gamma_{t} \in(0,1)$ is the point elasticity of $w_{t}$ with respect to $p_{t} \cdot{ }^{37}$

Lemma 2 If $(A 1),(29)$ and $B_{t}>b_{t}^{P}=0$ are satisfied, the desirable price for landlords of generation $t, p_{t+1}^{R}$, is either $p^{w}$ (free trade) or $p_{t+1}^{c}$ (autarky).

Proof. Since $\left(1-\gamma_{t}\right)$ decreases with $H_{t}^{A}$, one can find from (29) and (34) that the objective function in (35) is non-monotonically sloped and is strictly convex with respect to $p_{t+1} \in(0, \infty)$, implying the result.

Next consider how landlords' wealth level affects their choice between free trade and autarky. In order to simplify the notation, let $z^{c}$ be variable $z$ in autarky and $z^{w}$ be the one under free trade. Recalling $b_{t}^{P}=0$ here, (33) yields $v_{t}^{R, c}=v^{R}\left(B_{t}, 0, p_{t+1}^{c}\right)$ and $v_{t}^{R, w}=v^{R}\left(B_{t}, 0, p^{w}\right)$, and the analysis below will demonstrate that $v_{t}^{R, c}$ and $v_{t}^{R, w}$ exhibit the properties as depicted in Figure 4. Observe in the diagram that the landlords' desired price depends on the level of aggregate transfer.

First we investigate the properties of $v_{t}^{R, c}$. (35) and the market-clearing condition (29) yield

$$
v_{t}^{R, c}=\epsilon y_{t+1}^{M, c} / \lambda \quad \text { for } B_{t}>0
$$

\footnotetext{
${ }^{37}$ The expression for $\gamma_{t}$ is given by (68) in the Appendix. One can get $\gamma_{t+1}$ by applying the implicit function theorem to $(23)$ to get $\kappa_{p}(\cdot)$ and to $(7)$ to get $H_{p}^{A}(\cdot)$, and also by noting $h^{\prime}\left(e_{t}\right)=\alpha /(1-\alpha) k_{t+1}$ from (15).
} 
Substituting (21), (22) and (32) into (3) produces

$$
y_{t+1}^{M, c}=M\left(B_{t}-\lambda e_{t}\right)^{\alpha}\left[\lambda h\left(e_{t}\right)+1-\lambda-H_{0}^{A}\right]^{1-\alpha},
$$

which is a strictly increasing, strictly concave, continuous function of a single variable $B_{t}$, satisfying the Inada conditions. ${ }^{38}$ Furthermore, $y_{t+1}^{M, c}$ diminishes towards zero as $B_{t}$ approaches zero because, as follows from (16) and (24), $K_{t+1}$ and $H_{t+1}$ respectively approach zero and one as $B_{t}$ approaches zero. Conversely, as $B_{t}$ goes to infinity, $K_{t+1}, H_{t+1}$ and thus $y_{t+1}^{M, c}$ go to infinity. These properties of $y_{t+1}^{M, c}$ are reflected in those of $v_{t}^{R, c}$ depicted in Figure 4 .

Next consider the properties of $v_{t}^{R, w}$. Industrial output under free trade, a component of $v_{t}^{R, w}$, is

$$
y_{t+1}^{M, w}=M\left(B_{t}-\lambda e_{t}\right)^{\alpha}\left[\lambda h\left(e_{t}\right)+1-\lambda-H_{t+1}^{A, w}\right]^{1-\alpha},
$$

where $H_{t+1}^{A, w} \equiv H^{A}\left(k_{t+1}^{w}, p^{w}\right)$ and $k_{t+1}^{w} \equiv \kappa\left(B_{t}, 0, p^{w}\right)$. Noting $e_{t}=\arg \max y_{t+1}^{M}$, one can find that for a given level of $B_{t}$, only the employment level in agriculture generates quantitative differences in industrial outputs under different trade policies. ${ }^{39}$ Let $B^{\text {min }}$ be a value of $B_{t}$ such that $p_{t+1}^{\max }=p^{w}$ for $b_{t}^{P}=0$. As shown in the Appendix, $p_{t+1}^{\max }$ is an increasing function of $B_{t}$, meaning that $p_{t+1}^{\max }<p^{w}$ for $B_{t} \in\left[0, B^{\mathrm{min}}\right]$ and $p^{w}<p_{t+1}^{\max }$ otherwise. It then follows from (26) that $y_{t+1}^{M, w}=0$ for $B_{t} \in\left[0, B^{\min }\right]$ and $y_{t+1}^{M, w}>0$ for $B_{t}>B^{\mathrm{min}}$.

Now, a landlord's net gain from free trade is expressed as

$$
v_{t}^{R, w}-v_{t}^{R, c}=\epsilon\left\{\left[y_{t+1}^{M, w}-y_{t+1}^{M, c}\right]+\left[p^{w} y_{t+1}^{A, w}-(1-\lambda) w_{t+1}^{w}-\lambda p^{w} \hat{c}\right]\right\} / \lambda,
$$

where the first and second square brackets respectively indicate the gains from the industrial sector and from the agricultural sector. Note that these two components are always opposite in their signs; in the case of industrial (agricultural) specialization, the gain from industry is positive (negative), whereas the gain from agriculture is negative (positive). This result reflects a trade-off between two assets - capital and land — in landlords' portfolios.

The overall effect of specialization depends on the wealth level $B_{t}$. In light of $(40),{ }^{40}$

$$
v_{t}^{R, w}=v_{t}^{R, c} \quad \text { and } \quad \partial v_{t}^{R, c} / \partial B_{t}>\partial v_{t}^{R, w} / \partial B_{t} \quad \text { for } B_{t}=\breve{B},
$$

\footnotetext{
${ }^{38}$ These properties are obtained from (4), (15) and (24), noting $\partial y_{t+1}^{M} / \partial B_{t}=R\left(k_{t+1}\right)$ and $e_{t}=\arg \max y_{t+1}^{M}$.

${ }^{39}$ For this reason, the superscripts of $e_{t}^{c}$ and $e_{t}^{w}$ can be ommitted to simplify the notation.

${ }^{40}$ The diffrence in $\partial v_{t}^{R} / \partial B_{t}$ is proven by the following two facts. First, the definition of $\breve{B}$ implies $\partial y_{t+1}^{M} / \partial B_{t}=$ $R\left(\kappa\left(\breve{B}, 0, p^{w}\right)\right)=R\left(\kappa\left(\breve{B}, 0, p_{t+1}^{c}\right)\right)$. Second, the difference $y_{t+1}^{A}-(1-\lambda) w_{t+1}$ decreases with $B_{t}$ because, as follows from (8), $H_{t+1}^{A}$ decreases with $k_{t+1}$ and thus $B_{t}$.
} 
where $\breve{B}$ is a unique value of $B_{t}$ for which $p_{t+1}^{c}=p^{c}\left(B_{t}\right)=p^{w}$. That is, landlords prefer autarky if $B_{t}$ is moderately greater than $\breve{B}$. Recalling $d p^{c}\left(B_{t}\right) / d B_{t}>0$ and $p^{c}\left(B_{t}\right)<p_{t+1}^{\max }$ for any $B_{t}>0$,

$$
p^{w}<p_{t+1}^{c}<p_{t+1}^{\max } \quad \text { for } B_{t}>\breve{B} \text { and } b_{t}^{P}=0 \text {. }
$$

Therefore, the economy has a comparative advantage (in period $t+1$ ) in manufacturing for $B_{t}>$ $\breve{B}$, and in agriculture for $B_{t}<\breve{B}$. A higher level of aggregate transfer leads to a larger difference between the domestic and world prices. If $B_{t}$ is not sufficiently greater than $\breve{B}$, specialization in industry with insufficient capital stocks does not bring them industrial profits enough to compensate for their losses in agriculture. On the other hand, as asserted by the following lemma, sufficient amounts of aggregate transfer induce landlords to vote for free trade.

Lemma 3 There exists a unique value $\tilde{B}$ such that

$$
v^{R}\left(B_{t}, 0, p^{w}\right)-v^{R}\left(B_{t}, 0, p_{t+1}^{c}\right) \begin{cases}<0 & \text { for } B_{t} \in(\breve{B}, \tilde{B}) \\ =0 & \text { for } B_{t}=\tilde{B} \\ >0 & \text { for } B_{t} \in(\tilde{B}, \infty)\end{cases}
$$

Proof. See the Appendix.

Group $R$ 's trade-policy preferences are illustrated in Figure $4 .{ }^{41}$ As will become apparent in Section 7, the diagram applies to the economy characterized by scarce land and a relatively large fraction of landlords. $\tilde{B}$ is the value of $B_{t}$ for which members of group $R$, the landed class, are indifferent between liberal and protective trade policies. They support anti-industrial protective policies for $B_{t} \in(\breve{B}, \tilde{B})$, pro-industrial liberal policies for $B_{t}>\tilde{B}$, and pro-agricultural liberal policies for $B_{t}<\breve{B}$.

\section{Globalization and Economic Development}

This section presents a non-monotonic evolution of trade policy that reflects gradual changes in individuals' trade-policy preferences and the extension of the franchise. This section confines its analysis to a land-scarce economy, which can be viewed as Western Europe. It will demonstrate that while the economy eventually liberalizes foreign trade, it may go through a stage of protectionism between two surges of liberalism, depending on the scarcity of land. Namely, a bifurcation of

\footnotetext{
${ }^{41} \breve{B}>B^{\min }$ in the diagram because $p_{t+1}^{c}<p_{t+1}^{\max }$ and both $p_{t+1}^{c}$ and $p_{t+1}^{\max }$ are increasing with $B_{t}$.
} 
trade policy may emerge in the growth process even among land-scarce economies. The case of land-abundant economies will be discussed in Section 7 .

We postulate that in each period, the franchise is given only to young individuals who receive transfers from their parents. They adopt a trade policy executed in the next period by majority voting. Since group $R$ is the minority (i.e., $\lambda<1 / 2$ ), as long as $b_{t}^{P}>0$ the political decision fully reflects group $P$ 's opinion. It follows from (33) that

$$
p_{t+1}=\left\{\begin{array}{ll}
p_{t+1}^{R} & \text { if } b_{t}^{R}>b_{t}^{P}=0 \\
p_{t+1}^{P} & \text { if } b_{t}^{P}>0 .
\end{array}\right\} \equiv p\left(B_{t}, b_{t}^{P}\right),
$$

As shown in (10) and (13), consumption and transfers depend on the income and price levels. Hence in light of (27) and (43), the evolution of the economy is governed by a two-dimensional, first-order, autonomous dynamical system in $B_{t}$ and $b_{t}^{P}$ :

$$
\begin{aligned}
& B_{t+1}=\beta\left(y_{t+1}-p_{t+1} C_{t+1}^{A}\right)=\phi\left(B_{t}, b_{t}^{P}, p_{t+1}\right)=\Phi\left(B_{t}, b_{t}^{P}\right) \\
& b_{t+1}^{P}=\beta \max \left(I_{t+1}^{P}-p_{t+1} \hat{c}, 0\right)=\psi\left(B_{t}, b_{t}^{P}, p_{t+1}\right)=\Psi\left(B_{t}, b_{t}^{P}\right),
\end{aligned}
$$

where $C_{t}^{A} \equiv \lambda c_{t}^{A, R}+(1-\lambda) c_{t}^{A, P}$ denotes the aggregate food consumption at time $t$.

In order to exclude development scenarios that are beyond this paper's scope, it is assumed that

$$
B_{0} \in(\breve{B}, \tilde{B}) ; \quad b_{0}^{P}=0 ; \quad p_{0}=p_{0}^{c}
$$

where $B_{0}=\beta M K_{0}^{\alpha}\left(1-H_{0}^{A}\right)^{1-\alpha}>0$ as follows from (29) and (44). The first condition above leads to both comparative advantage in manufacturing and landlords' preference of autarky over free trade in period 1. The second and third conditions imply that (29) is satisfied.

Let $\hat{B}$ be the critical value for which unskilled proletarians can afford just the food consumption level $\hat{c}$ under free trade. Namely, ${ }^{42}$

$$
w(\hat{k})=p^{w} \hat{c}, \quad \text { where } \hat{k} \equiv \kappa\left(\hat{B}, 0, p^{w}\right) .
$$

Let $B^{\prime}$ be a value such that $p_{t+1}^{c}>p^{w}$ for all $B_{t}>B^{\prime}$ and $b_{t}^{P} \in\left[0, B_{t}\right){ }^{43}$ The analysis in what follows is limited to the case

$$
\max \left(B^{\prime}, \tilde{B}\right)<\hat{B}
$$

${ }^{42}$ The properties of $\kappa(\cdot)$ in $(24)$ ensure that $\hat{B}$ is uniquely defined.

${ }^{43}$ Noting $B^{*}$ defined below, $B^{\prime}$ is a value which is sufficiently close to $B^{*}$. 
Consistent with the historical evidence, the condition $B^{\prime}<\hat{B}$ keeps the economy's comparative advantage in manufacturing over time, and the condition $\tilde{B}<\hat{B}$ makes the food constraint binding for group $P$ in the first period of trade liberalization. ${ }^{44}$

Figure 3 depicts the conditional dynamical system formed by $B_{t+1}=\phi\left(B_{t}, b_{t}^{P}, p^{w}\right)$ and $b_{t+1}^{P}=$ $\psi\left(B_{t}, b_{t}^{P}, p^{w}\right)$ on the $\left(B_{t}, b_{t}^{P}\right)$ space defined as $\mathbb{R}_{++} \times\left[0, B_{t}\right)$. Given the fixed world price, $B_{t+1}=B_{t}$ and $b_{t+1}^{P}=b_{t}^{P}$ along the $B B$ locus and the $b b$ locus, respectively. Given the initial condition above, the pair $\left(B_{t}, b_{t}^{P}\right)$ never enters the region above the $45^{\circ}$ line, as was established in Corollary 1.

\subsection{Stage I - Dominance of the Landed Class and Resistance to Free Trade}

The economy develops in Stage I at time $t \in[0, \tilde{t}]$, where $\tilde{t}$ is the period such that $B_{t} \leq \tilde{B}$ for all $t<\tilde{t}$ and $B_{t}>\tilde{B}$ for $t=\tilde{t}$. Note that (A2) implies $\tilde{t}>0$. In this early stage of development, the food constraint is binding for members of group $P$ and political power is in the hands of the landed interest, who resist trade liberalization.

\subsubsection{The Evolution of the Economy}

The initial pair of transfers is $B_{0} \in(\breve{B}, \tilde{B})$ and $b_{t}^{P}=0$ as given by (A2). In addition, Lemmas 2-3 and (43) yield

$$
p_{t+1}=p_{t+1}^{R}=p_{t+1}^{c} \quad \text { for } B_{t} \in[\breve{B}, \tilde{B}] \text { and } b_{t}^{P}=0
$$

assuming that landowners vote for a protective policy when they are indifferent. It thus follows from (28), (37) and Lemma 1 that for these pairs of transfers, (44) becomes

$$
\begin{aligned}
& B_{t+1}=\phi\left(B_{t}, 0, p_{t+1}^{c}\right)=\beta y_{t+1}^{M}=\beta \lambda v^{R}\left(B_{t}, 0, p_{t+1}^{c}\right) / \epsilon ; \\
& b_{t+1}^{P}=\psi\left(B_{t}, 0, p_{t+1}^{c}\right)=\beta \max \left(w_{t+1}-p_{t+1}^{c} \hat{c}, 0\right)=0,
\end{aligned}
$$

where the last equality on the first line is based on (37). ${ }^{45}$ The properties of $v^{R}\left(B_{t}, 0, p_{t+1}^{c}\right)$ are explained in Subsection 5.2 and are depicted in Figure 4.

Let $B^{*}$ be a value of $B_{t}$ for which $p^{w} F_{H}(X, 0)=w\left(k_{t+1}\right)$ or equivalently $p^{\min }\left(k_{t+1}\right)=p^{w}$, where $k_{t+1}=k\left(B_{t}, b_{t}^{P}, p^{w}, 1\right) .{ }^{46}$ It follows from (24) and (26) and that $p_{t+1}^{\min }>p^{w}$ for $B_{t}>B^{*}$ and

\footnotetext{
${ }^{44}$ The feasibility of the condition (A3) can be proven as follows. Consider the case in which $\tilde{c}$ goes to infinity and $\alpha$ approaches 1 , while $(1-\alpha) / p^{w}$ remains constant. First, in light of $(45), \hat{B}$ becomes infinitely large. Second, noting that $B^{*}$ remains finite, one can find a value of $B^{\prime}$ which is smaller than $\hat{B}$. Third and finally, noting that opening up to international trade raises the capital labor ratio $k_{t+1}$, one can find from (40) and (41) that $\tilde{B} \rightarrow \breve{B}$, whereas $\breve{B}$ remains constant because of $(28)$ and $p^{c}(\breve{B})=p^{w}$.

${ }^{45} y_{t+1}^{M, c}$ in $(37)$ is denoted as $y_{t+1}^{M}$ in this section to simplify the notation.

${ }^{46} B^{*}$ is independent of $b_{t}^{P}$ because (24) shows that $b_{t}^{P}$ has no effect on $k\left(B_{t}, b_{t}^{P}, p^{w}, 1\right)$. Also, $B^{*}$ is independent of $X$ because $F_{H}(X, 0)=(1-a)^{1 / \rho}$.
} 
$b_{t}^{P} \in\left[0, B_{t}\right)$, meaning complete specialization in manufacturing under free trade.

In order to assure that the economy goes through all phases of globalization, the technological level of manufacturing, $M$, is assumed to be high enough to satisfy

$$
B_{t}<\alpha \beta M\left(B_{t}-\lambda e_{t}\right)^{\alpha}\left[\lambda h\left(e_{t}\right)+1-\lambda-H_{0}^{A}\right]^{1-\alpha} \quad \text { for } B_{t}=\hat{B}, B^{*}
$$

where on the right-hand side is $\beta$ times the rental income on capital $R_{t+1} K_{t+1}$ that would be if the dynamical system (46) operated for $B_{t}=\hat{B}, B^{*}$ and $b_{t}^{P}=0 .{ }^{47}$

Given the properties of $v^{R}\left(B_{t}, 0, p_{t+1}^{c}\right)$, the condition above leads to

$$
B_{t}<\phi\left(B_{t}, 0, p_{t+1}^{c}\right) \quad \text { for } 0<B_{t} \leq \max \left(\hat{B}, B^{*}\right)
$$

It follows that $B_{t+1}>B_{t}$ in the time interval $[0, \tilde{t}]$ and the economy eventually departs from Stage I. This monotonic growth in $B_{t}$ yields $y_{t+1}^{M}>y_{t}^{M}, y_{t+1}^{A}=y_{t}^{A}$ and $y_{t+1}>y_{t}$ for $t \in[0, \tilde{t}]$.

\subsubsection{Class Conflict}

The above analysis and (42) lead to

$$
p_{t}=p_{t}^{R}=p_{t}^{c}>p^{w} ; \quad c_{t}^{A, P}=c_{0}^{A, P}<\hat{c} ; \quad b_{t}^{P}=0, \quad \text { for } t \in[0, \tilde{t}],
$$

where $c_{0}^{A, P}=F_{H}\left(X, H_{0}^{A}\right)$. Note that the food constraint is binding for members of group $P$.

The two groups have conflicting viewpoints regarding the trade policy in Stage I. Trade liberalization is beneficial for members of group $P$, whose incomes are entirely devoted to the agricultural consumption. A decline in the price from the autarkic level leads to a decline in the agricultural employment and an increase in the wage in terms of the agricultural good, $F_{H}\left(X, H_{t}^{A}\right)$. However, the franchise is not given to group $P$ in this immature development stage and their agricultural consumption is suppressed at the autarkic price level. Proposition 1 summarizes the discussion.

Proposition 1 Under $(A 1)-(A 4), p_{t}=p_{t}^{R}=p_{t}^{c}>p^{w}=p_{t}^{P}$ in the time interval $[0, \tilde{t}]$.

\subsection{Stage II - The First Globalization}

The economy develops in Stage II for period $t \in(\tilde{t}, \hat{t}]$, where $\hat{t}$ is the period such that $B_{t} \leq \hat{B}$ for all $t<\hat{t}$ and $B_{t}>\hat{B}$ for $t=\hat{t}$. As in Stage I, the subsistence constraint is binding for members of

\footnotetext{
${ }^{47}$ The condition (A4) holds given a sufficiently high level of $M$, noting that both $\hat{B}$ and $B^{*}$ go to zero as $M$ becomes infinitely large.
} 
group $P$ and the political system is dominated by the landed class. Unlike in Stage I, however, trade liberalization brings about an increase in the labor employment and output of the manufacturing sector enough to alter landlords' attitudes towards trade policies. The economy accordingly opens up to international trade.

\subsubsection{The Evolution of the Economy}

In the first period of Stage II, $B_{\tilde{t}} \in(\tilde{B}, \hat{B}]$ by definition and $b_{\tilde{t}}^{P}=0$ from (48). In view of Lemmas $2-3$ and (43),

$$
p_{t+1}=p_{t+1}^{R}=p^{w} \quad \text { for } B_{t} \in(\tilde{B}, \hat{B}] \text { and } b_{t}^{P}=0 \text {. }
$$

For this set of transfers, $I_{t+1}^{P}=w_{t+1} \leq p^{w} \hat{c}$ by noting (19) and the definition of $\hat{B}$. Thus in light of (14) and (27), (44) becomes

$$
\begin{aligned}
& B_{t+1}=\phi\left(B_{t}, 0, p^{w}\right)=\beta \lambda v^{R}\left(B_{t}, 0, p^{w}\right) / \epsilon \\
& b_{t+1}^{P}=\psi\left(B_{t}, 0, p^{w}\right)=\beta \max \left(w_{t+1}-p^{w} \hat{c}, 0\right)=0 .
\end{aligned}
$$

The properties of $v^{R}\left(B_{t}, 0, p^{w}\right)$ are illustrated in Figure 4. $v^{R}\left(B_{t}, 0, p^{w}\right)$ is greater than $v^{R}\left(B_{t}, 0, p_{t+1}^{c}\right)$ for $B_{t}>\tilde{B}$, implying a higher path of $B_{t}$ under free trade than in autarky. This means that, recalling (47),

$$
B_{t}<\phi\left(B_{t}, 0, p^{w}\right) \quad \text { for } \tilde{B} \leq B_{t} \leq \max \left(\hat{B}, B^{*}\right)
$$

Since $v^{R}\left(B_{t}, 0, p^{w}\right)$ is increasing in $B_{t}$, it follows that $B_{t+1}>B_{t}$ for $t \in[\tilde{t}, \hat{t}]$ and $B_{t}$ exceeds $\hat{B}$ within finite time. As depicted in Figure 3, the pair $\left(B_{t}, b_{t}^{P}\right)$ moves rightwards on the interval $(\tilde{B}, \hat{B}]$ of the horizontal axis - a portion of the $b b$ locus - in Stage II.

As $B_{t}$ and thus $k_{t+1}$ are rising over time, the employment of human capital is increasing in the manufacturing sector and is decreasing in the agricultural sector. Hence, (1), (27) and (39) yield $y_{t+1}^{M}>y_{t}^{M}, y_{t+1}^{A}<y_{t}^{A}$ and $y_{t+1}>y_{t}$ for $t \in(\tilde{t}, \hat{t}]$.

\subsubsection{Class Conflict}

The above analysis and (42) lead to

$$
p_{t}=p_{t}^{R}=p^{w}<p_{t}^{c} ; \quad c_{t}^{A, P} \in\left(c_{t-1}^{A, P}, \hat{c}\right) ; \quad b_{t}^{P}=0 \quad \text { for } t \in(\tilde{t}, \hat{t}]
$$

where $c_{t}^{A, P}=F_{H}\left(X, H_{t}^{A}\right)$. Note that the food constraint is still binding for group $P$. 
In Stage II, the two groups share the same viewpoint regarding the trade policy, while the franchise is still limited to group $R$. Due to the difference between the world-market and autarkic prices, opening up to international trade decreases the employment in agriculture and thereby breaks the agrarian equilibrium (29), in which the living standard of the masses is suppressed. The resultant improvement in $F_{H}(\cdot)$, the wage in terms of food, enhances group $P$ 's food consumption. For this reason, a liberal policy is desirable for group $P$ as well as for group $R$. Proposition 2 summarizes the discussion.

Proposition 2 Under $(A 1)-(A 4), p_{t}=p^{w}=p_{t}^{P}=p_{t}^{R}$ in the time interval $(\tilde{t}, \hat{t}]$.

The monotonic growth of $c_{t}^{A, P}$ in (51) is driven by the accumulation of aggregate transfer, which enhances the capital-labor ratio in industry and thereby decreases the labor employment of the agricultural sector. Through this process the wage rage $F_{H}(\cdot)$ exceeds the subsistence consumption level $\hat{c}$ in period $\hat{t}+1$.

\subsection{Stage III - The Rise of the Working Class and Political Backlash}

The economy develops in Stage III for period $t \in\left(\hat{t}, t^{*}\right)$, where $t^{*}$ is the period such that under free trade, $b_{t}^{P}<e_{t}$ for all $t<t^{*}$ and $b_{t}^{P} \geq e_{t}$ for $t=t^{*}$. Noting $k_{p}(\cdot) \geq 0$ in $(24)$, the credit constraint remains binding on group $P$ for any feasible price $p_{t+1} \in\left[p^{w}, p_{t+1}^{c}\right]$. On the other hand, unlike in the previous stages the food constraint is no longer binding, the franchise is given to all adults in society, and the landless workers invest in education. However, their wealth levels are still too low to nullify the credit constraint and to invest in physical capital. The increasing demand for the manufactured good may prompt the mass to be protectionist against the inflow of staple food.

It follows from (50) and (51) that in the first period of Stage III, $\hat{t}+1$,

$$
B_{\hat{t}+1}>\hat{B}, \quad b_{\hat{t}+1}^{P}>0, \quad \text { and } \quad p_{\hat{t}+1}=p_{\hat{t}+1}^{R}=p^{w} .
$$

\subsubsection{Conditional Dynamics}

In order to facilitate the analysis of unconditional dynamics, first consider the evolution of the economy conditional on $p_{t+1}=p^{w}$ for all $t>\hat{t}$. The lemma below asserts that there is no $b b$ locus

and $b_{t}^{P}$ grows monotonically on the subspace $[\hat{B}, \bar{B}] \times\left[0, B_{t}\right)$ in Figure 3. A level of aggregate transfer $\bar{B}$ in the lemma will be specified later. 
Lemma 4 Under $(A 1)-(A 4), \psi\left(B_{t}, b_{t}^{P}, p^{w}\right) \geq b_{t}^{P}$ for $B_{t} \in[\hat{B}, \bar{B}]$ and $b_{t}^{P} \in\left[0, B_{t}\right)$, with equality only for $B_{t}=\hat{B}$ and $b_{t}^{P}=0$.

Proof. See the Appendix

Hence, for $B_{t} \in[\hat{B}, \bar{B}]$ and $b_{t}^{P} \in\left[0, e_{t}\right)$, all members of generation $t$ consume $\hat{c}$ units of food whereas the credit constraint is binding for group $P{ }^{48}$ In this case $\theta_{t}=\lambda$ and the evolution of aggregate transfer in (44) becomes

$$
B_{t+1}=\phi\left(B_{t}, b_{t}^{P}, p^{w}\right)=\beta\left(y_{t+1}-p^{w} \hat{c}\right)
$$

where in view of $(27)$,

$$
\phi_{B}(\cdot)=\beta R_{t+1}>0 ; \quad \phi_{B B}(\cdot)<0 ; \quad \phi_{b}(\cdot)>0
$$

Figure 3 geometrically represents the conditional dynamical system in the subspace where $B_{t} \in$ $[\hat{B}, \bar{B}]$ and $b_{t}^{P} \in\left[0, e_{t}\right)$. One can find from (50) and (54) that

$$
\phi\left(\hat{B}, b_{t}^{P}, p^{w}\right)>\hat{B} \quad \text { for } b_{t}^{P} \in\left[0, e_{t}\right) .
$$

Given these properties of $\phi(\cdot)$ and the initial condition (52), the aggregate transfer increases monotonically over time towards the positively sloped $B B$ locus, along which $B_{t} \in(\hat{B}, \bar{B})$. It thus follows from Lemma 4 that $b_{t}^{P}$ also increases monotonically over time, eventually exceeding $e_{t}\left(<B_{t}\right)$.

\subsubsection{Unconditional Dynamics}

The nature of the unconditional dynamics depends on the price level determined in accordance with (43). Recalling (27),

$$
p^{w}=\arg \max \left[y\left(B_{t}, b_{t}^{P}, p_{t+1}\right)-p_{t+1} \hat{c}\right]
$$

where $p_{t+1} \in\left[p^{w}, p_{t+1}^{c}\right]$. It follows from (44) that a liberal policy maximizes aggregate transfer in the absence of the food constraint.

Lemma 5 If $(A 1)-(A 4)$ are satisfied and $X$ is sufficiently small, then

$$
0<b_{t}^{P}<b_{t+1}^{P}<\bar{b}^{P} \quad \text { and } \quad \hat{B}<B_{t+1}<\bar{B} \quad \text { for } t \in\left(\hat{t}, t^{*}\right) .
$$

\footnotetext{
${ }^{48}$ As implied by Lemma 4 and Corollary $1, I_{t+1}^{R}>I_{t+1}^{P} \geq p^{w} \hat{c}$ in this case. Hence $C_{t+1}^{A}=\hat{c}$. As follows from (A3), if $B_{t}$ is greater than $\hat{B}$, the manufacturing sector operates and $K_{t+1}>0$. A positive amount of capital requires that members $R$ of generation $t$ are not credit-constrained.
} 
Proof. Consider the first period of Stage III, $t=\hat{t}+1$, which is characterized by (52). Using (33) and (43) with (19) and Lemma 4, one can obtain

$$
p_{t+1}=p_{t+1}^{P}=\arg \max \left[w_{t+1} h\left(b_{t}^{P}\right)-p_{t+1} \hat{c}\right]
$$

implying that $p_{t+1}=\arg \max \psi(\cdot)$. If $p_{t+1}$ is sufficiently close to $p^{w}$, one can apply (55) to show that $\phi\left(\hat{B}, b_{t}^{P}, p_{t+1}\right)>\hat{B}$ for $b_{t}^{P}<\hat{B}$. In this case $\hat{B}<B_{t+1}<\bar{B}$, where the second inequality is implied by (56). Such a low price level is chosen by group $P$ because $H_{t+1}^{A} \rightarrow 0$ and $\gamma_{t+1} \rightarrow 0$ in (36) as $X \rightarrow 0$ for a given triplet $\left(B_{t}, b_{t}^{P}, p_{t+1}\right)$. Therefore, it follows from Lemma 4 that as in the conditional dynamics, $b_{t}^{P}$ grows monotonically over time and ultimately exceeds $e_{t}$.

As shown in (57), the desirable price for members of group $P$ maximizes $\left[w_{t+1} h\left(b_{t}^{P}\right)-p_{t+1} \hat{c}\right]$. Note that the objective function includes the wage in terms of the manufactured good, $w_{t+1}$, because members of group $P$ consume the manufactured good as well as the agricultural good. Raising the relative price promotes intersectoral labor shifts from industry to agriculture, and accordingly increases $k_{t+1}$ and $w_{t+1}$. For this reason, free trade is not necessarily most desirable for them. As shown above, the desirable price for group $P$ depends on the level of $\gamma_{t+1}$.

Proposition 3 If (A1)-(A4) are satisfied, moderatelyland-scarce economies are likely to experience political backlash against liberalism in Stage III, where severelyland-scarce economies will maintain liberalism.

Proof. (68) in the Appendix reveals that for a given triplet $\left(B_{t}, b_{t}^{P}, p^{w}\right), \gamma_{t+1}$ increases with $X$ because $H_{t+1}^{A}, X / H_{t+1}^{A}$ and $k_{t+1}$ increase with $X$ whereas $H_{t+1}^{M}$ decreases with $X$. In addition, $\gamma_{t+1}$ can be sufficiently close to 1 depending on the structural parameter; e.g., $\gamma_{t+1} \rightarrow 1$ as $a \rightarrow 0$. Hence the results follow from the proof of Lemma 5, noting that an excessively land-abundant economy becomes too protectionist to depart from Stage III.

The mechanism behind the resurgence of protectionism can be explained in the following manner. Given a larger amount of land, a change in the relative price has a bigger impact on the wage in terms of the manufactured good, $w_{t}$, because both $\gamma_{t}$ and $F_{H}(\cdot)$ increase with $X$. Under this circumstance, workers find optimal to balance the consumption of these two goods by a centrist policy, rather than to maximize only food consumption by an extremely liberal policy.

The proposition above asserts a possibility of a bifurcation of trade policy among land-scarce economies in Stage III. Severe political backlash will retard the accumulation of aggregate transfer, 
and the resultant decline in the wage rate $w_{t+1}$ reactivates the food constraint on group $P$, bringing the economy back to the previous stages. In order to assure the economy's departure from Stage III, agricultural land is assumed to be sufficiently small.

The evolution of aggregate output depends on the executed trade policy. As shown in the analysis of the conditional dynamics, a liberal policy will continue to raise aggregate transfers and hence aggregate output. On the other hand, a protectionist policy does not guarantee their monotonic growth.

\subsubsection{Class Conflict}

It will be shown that the protectionist policy adopted by moderately land-scarce economies causes class conflicts between growing workers and landowners, who can be regarded as big capitalists in this stage.

Lemma 6 If $(A 1)-(A 4)$ are satisfied and $p_{t+1}^{P}>p^{w}$ in period $t \in\left(\hat{t}, t^{*}\right)$, then $p_{t+1}^{R}=p^{w}$ in the period.

Proof. Follows from Corollary 1 and (57). $p_{t+1}^{i}=\arg \max \left(I_{t+1}^{i}-p_{t+1} \hat{c}\right)$ in period $t \in\left(\hat{t}, t^{*}\right)$. Note that $p^{w} \neq p_{t+1}^{P}$ whereas $p^{w}=\arg \max \left(y_{t+1}-p_{t+1} \hat{c}\right)$ from (56). The result therefore follows from and (27).

Hence, the two groups never agree on protectionist policies in Stage III.

Proposition 4 If (A1)-(A4) are satisfied, then moderately land-scarce economies are likely to have $p_{t+1}=p_{t+1}^{P}>p_{t+1}^{R}=p^{w}$ in the time interval $\left(\hat{t}, t^{*}\right)$.

Proof. Follows from Proposition 3 and Lemma 6.

It deserves special emphasis that political backlash to protectionism in Stage III is supported not by capitalists but by workers, who are better off. ${ }^{49}$

\subsection{Stage IV - The Second Globalization}

The economy develops in Stage IV for period $t \geq t^{*}$. The food constraint is not binding as in Stage III, and moreover, the credit constraint dissipates in the long run. In the absence of the two

\footnotetext{
${ }^{49}$ While landowners are homogeneous in this model, it is plausible to consider that in reality, protective policy was suppoted by large-size landlords, whose landownership is their dominant income source. As shown in (52), the first period of Stage III, $t+1$, is a transitionary period in which the ongoing trade policy was determined by adult members of group $R$, while young members of group $P$ has obtained voting rights for the next periods' trade policy.
} 
constraints, all individuals have savings and the interest rate positively affects their rental incomes on capital. The positive effect of trade liberalization on the interest rate will outweigh its negative effect on the wage rate at highly developed stages, swaying countries towards liberalism.

It follows from Lemma 5 with (52) and (A3) that in the first period of Stage IV, $t^{*}$,

$$
B_{t^{*}}>\hat{B}, \quad b_{t^{*}}^{P} \geq e_{t^{*}}, \quad \text { and } \quad p_{t^{*}} \in\left[p^{w}, p_{t^{*}}^{c}\right]
$$

\subsubsection{Conditional Dynamics}

In order to facilitate the analysis of the dynamical system, first consider the evolution of transfers conditional on $p_{t+1}=p^{w}$ for $t \geq t^{*}$. It follows from Corollary 1 and Lemma 4 that for $B_{t} \in[\hat{B}, \bar{B}]$ and $b_{t}^{P} \geq e_{t}$, no constraint is binding and $\theta_{t}=1$. In this case (44) becomes

$$
\begin{aligned}
& B_{t+1}=\phi\left(B_{t}, b_{t}^{P}, p^{w}\right)=\beta\left(y_{t+1}-p^{w} \hat{c}\right) \\
& b_{t+1}^{P}=\psi\left(B_{t}, b_{t}^{P}, p^{w}\right)=\beta\left(I_{t+1}^{P}-p^{w} \hat{c}\right)
\end{aligned}
$$

where in view of (27) and (19),

$$
\begin{array}{ll}
\phi_{B}(\cdot)=\beta R_{t+1}>0 ; \quad \phi_{B B}(\cdot)<0 ; & \phi_{b}(\cdot)=0 ; \quad \lim _{B_{t} \rightarrow \infty} \phi_{B}(\cdot)=0 \\
\psi_{B}(\cdot)>0 ; \quad \psi_{b}(\cdot)=\beta R_{t+1}>0 ; & \psi_{b b}(\cdot)=0 .
\end{array}
$$

Note that the interest rate $R_{t+1}$ is the additional factor through which trade policies affect $I_{t+1}^{P}$.

The lemma below reflects valueless landownership and the associated dissipation of wealth inequality under complete specialization in manufacturing.

Lemma 7 If (A1)-(A4) are satisfied, the conditional dynamical system (59) has a unique, nontrivial steady-state equilibrium $\left(\bar{B}, \bar{b}^{P}\right)$ such that

$$
\bar{B}=\phi\left(\bar{B}, \bar{b}^{P}, p^{w}\right)=\bar{b}^{P}=\psi\left(\bar{B}, \bar{b}^{P}, p^{w}\right)>\max \left(\hat{B}, B^{*}\right)
$$

Proof. Suppose $b_{t}^{P} \geq e_{t}$. Then (A4) and (60) yield a unique steady-state aggregate transfer $\bar{B}=\phi\left(\bar{B}, b_{t}^{P}, p^{w}\right)>\max \left(\hat{B}, B^{*}\right)$. Since $\bar{B}$ and the associated capital-labor ratio $\bar{k}=k\left(\bar{B}, b_{t}^{P}, p^{w}, 1\right)$ are independent of $b_{t}^{P}$, (60)-(61) yield

$$
\phi_{B}\left(\bar{B}, b_{t}^{P}, p^{w}\right)=\psi_{b}\left(\bar{B}, b_{t}^{P}, p^{w}\right)=\beta R(\bar{k})<1,
$$


implying a unique steady-state value $\bar{b}^{P}=\phi\left(\bar{B}, \bar{b}^{P}, p^{w}\right)$. In the steady state where $\bar{B}>B^{*}$, agricultural output is zero and aggregate output is $w(\bar{k}) h(e(\bar{k}))+R(\bar{k})[\bar{B}-e(\bar{k})]$. Hence noting (59), one can find that $\bar{B}=\bar{b}^{P}>e(\bar{k})$, establishing the lemma.

Figure 3 geometrically represents the conditional dynamical system (59) in the subspace where $B_{t} \in[\hat{B}, \bar{B}]$ and $b_{t}^{P} \in\left[e_{t}, B_{t}\right)$. This is the region where neither food nor credit constraints are binding. The upper $b b$ locus in the diagram is negatively sloped and has a unique intersection with the $45^{\circ}$ line at point $\left(\bar{B}, \bar{b}^{P}\right) .{ }^{50}$ One can find from $(55)$ and $(60)$ that

$$
\phi\left(\hat{B}, b_{t}^{P}, p^{w}\right)>\hat{B} \quad \text { for } b_{t}^{P} \in\left[e_{t}, B_{t}\right)
$$

This implies that given the initial condition (58), aggregate transfer $B_{t}$ increases monotonically over time towards the vertical $B B$ locus. It thus follows from Lemma 4 that $b_{t}^{P}$ also increases monotonically over time. As follows from $(62)$, the pair $\left(B_{t}, b_{t}^{P}\right)$ converges to a steady-state equilibrium $\left(\bar{B}, \bar{b}^{P}\right) .{ }^{51}$ Throughout Stage IV $, y_{t}, y_{t}^{M}$ and $k_{t}$ monotonically increase whereas $y_{t}^{A}$ monotonically decreases and reaches zero in the long run.

\subsubsection{Unconditional Dynamics}

As in Stage III, the nature of the unconditional dynamics depends on the price level determined by (43). A protective trade policy retards industrialization, although it may profit some members in society.

Lemma 8 If $(A 1)-(A 4)$ are satisfied and $X$ is sufficiently small, then

$$
0<b_{t}^{P}<b_{t+1}^{P}<\bar{b}^{P} \quad \text { and } \quad \hat{B}<B_{t+1}<\bar{B} \quad \text { for } t \geq t^{*}
$$

and $b_{t}^{P} \rightarrow B_{t}$ as $t \rightarrow \infty$.

Proof. It follows from (19) that, for $b_{t}^{P}>e_{t}$,

$$
\partial I_{t+1}^{P} / \partial p_{t+1}=\gamma_{t+1} F_{H}\left(X, H_{t+1}^{A}\right)\left[H_{t+1}^{A}+\left(B_{t}-b_{t}^{P}\right) / k_{t+1}\right]
$$

where the amount in the square bracket is smaller than $h\left(e_{t}\right)$. Then noting $(63)$, the result can be proven in the same way as the one for Lemma 5.

\footnotetext{
${ }^{50}$ Appying the implicit function theorem to (59), one can find that the $b b$ locus is negatively sloped over the range of $B_{t}$ where $\beta R\left(k\left(B_{t}, b_{t}^{P}, p^{w}, 1\right)\right)<1$. Note that $\beta R(\bar{k})<1$, as shown in the proof of Lemma 7 .

${ }^{51}$ Although $b_{t}^{P}$ may temporarily become smaller than $e_{t}$ in a period $t>t^{*}$, Lemma 4 and the fact $B_{t} \in\left(e_{t}, \bar{B}\right)$ assure that $b_{t}^{P}>e_{t}$ in the long run.
} 
The difference $B_{t}-b_{t}^{P}$ negatively correlates with a member $R$ 's capital income $R_{t+1} s_{t}^{P}$. Hence, when the difference is sufficiently small, a rise in $p_{t+1}$ raises the capital-labor ratio $k_{t+1}$ and thereby decreases her capital income, offsetting its positive effect on the wage rate (i.e., $\partial I_{t+1}^{P} / \partial p_{t+1}$ in (64) becomes small). In this circumstance, group $P$ is likely to support a liberal policy.

Proposition 5 If $(A 1)-(A 4)$ are satisfied and $X$ is sufficiently small, the economy converges to a steady-state equilibrium $\left(\bar{B}, \bar{b}^{P}, p^{w}\right)$.

Proof. Note that $F_{H}\left(X, H_{t+1}^{A}\right) H_{t+1}^{A}<\hat{c}$ in (64) due to the specialization in manufacturing and the linear homogeneity of the production function (1). Moreover, (23) implies that if $B_{t}-b_{t}^{P}$ is sufficiently small, then $b_{t}^{P}>e_{t}$ and $\theta_{t}=1$. It thus follows from Lemma 8 that $b_{t}^{P}>e_{t}$ and $p_{t+1}=p_{t+1}^{P}=p^{w}$ in the long run. The unconditional dynamical system then becomes equivalent to the conditional dynamical system, establishing the result.

Hence, despite the possibility of temporary political backlash, the economy will liberalize foreign trade in the long run. The eventual return to liberalism should be interpreted as a prediction of the trade policy in unreached, highly-developed stages, due to the fact that most currently developed countries still protect agriculture. After the permanent trade liberalization, $y_{t}, y_{t}^{M}$ and $k_{t}$ monotonically increase as in the case of conditional dynamics.

Proposition 6 Under $(A 1)-(A 4)$, the triplet $\left(\bar{B}, \bar{b}^{P}, p^{w}\right)$ maximizes long-run industrial output.

Proof. As shown earlier, free trade maximizes aggregate transfer and there is no steady state in Stage II. Hence, noting $y_{B}(\cdot)>0$ in $(27)$, there is no food constraint in the long-run when industrial output is maximized. Then one can use (56) to show that $p^{w}=\arg \max \phi\left(B_{t}, b_{t}^{P}, p_{t+1}\right)$. In addition, (44) yields $\phi_{b}(\cdot) \geq 0$ with equality only if $b_{t}^{P} \geq e_{t}$. Hence the pair $\left(\bar{b}^{P}, p^{w}\right)$ generates the maximized level of long-run aggregate transfer, which is $\bar{B}$. Finally, $\bar{B}$ maximizes industrial output because of $\bar{B}>B^{*}$.

This proposition and the analysis of Stages II-IV reveal that a permanent free-trade policy after Stage I results in maximizing long-run industrial output. Note that trade liberalization in Stage I may prevent economic take-off and hence industrialization. Such a hasty reform may discourage the accumulation of physical and human capital by reducing the incomes of landlords, who own the entire assets in Stage I. 


\subsubsection{Class Conflict}

Proposition 7 If $(A 1)-(A 4)$ are satisfied and $X$ is sufficiently small, $p_{t}=p^{w}=p_{t}^{P}=p_{t}^{R}$ in the long run.

Proof. The first two equalities are shown in the proof of Lemma 5. Around the steady-state equilibrium $\left(\bar{B}, \bar{b}^{P}, p^{w}\right)$, agricultural output is zero and thus $I_{t+1}^{R} / \partial p_{t+1}$ is obtained from (64) by replacing $b_{t}^{P}$ with $b_{t}^{R}$. The result therefore follows from Lemma 5 .

Hence, all members will ultimately agree on a free-trade policy in this land-scarce economy.

\section{Divergence}

This section discusses the role of the landed class in early take-off in economic development. For this purpose, consider two countries, A and B:

- Country $\mathrm{A}$ is the one considered in Section 6, satisfying $(A 1)-(A 4)$.

- Country B is identical to Country A except that the former has a larger amount of land per landlord, $x^{R}$.

Lemma 9 (a) If $X$ is sufficiently large, $B_{t}>\phi\left(B_{t}, 0, p_{t+1}^{c}\right)$ for $B_{t}=\tilde{B}$.

(b) $\tilde{B}$ decreases with the fraction of landlords, $\lambda$.

Proof. (a) Recalling that $p^{c}(\breve{B})=p^{w}$, where $p^{c}(\cdot)$ is defined in relation to (32), one can find that $p^{w} F_{H}\left(X, H_{0}^{A}\right)=w\left(\kappa\left(\breve{B}, 0, p^{w}\right)\right)$. It then follows from (2), (4) and (24) that $\breve{B} \rightarrow \infty$ as $X \rightarrow \infty$. On the other hand, (38) and (46) reveal that as $X \rightarrow \infty, \phi\left(B_{t}, 0, p_{t+1}^{c}\right)$ remains finite for any $B_{t}>0$. Hence the result follows from the fact $\breve{B}<\tilde{B}$ and the Inada condition of $\phi\left(B_{t}, 0, p_{t+1}^{c}\right)$.

(b) The result follows from (40), noting that $\partial v_{t}^{R, c} / \partial B_{t}<\partial v_{t}^{R, w} / \partial B_{t}$ for $B_{t}=\tilde{B}$.

Hence, sufficiently large values of $x^{R}$ prevent the economic take-off in Stage II.

Proposition 8 (Income Divergence) (a) Country A turns to pro-industrial a free trade policy in Stage II. The resulting decline in the food price promotes widespread investment, leading the country to Stage IV.

(b) Country $B$ tends to stagnate in Stage I, where an anti-industrial, protectionist policy is adopted. 
Proof. (a) The result follows from the discussion in Section 6. (b) As follows from Lemma 9 and (A4), there exists a value $B_{t} \in(\breve{B}, \tilde{B})$ such that $B_{t}=\phi\left(B_{t}, 0, p^{w}\right)$ if $\lambda$ is smaller and $X$ is not excessively larger than those of Country A. Hence the economy remains in Stage I and the result follows.

In Country A, a pro-industrial free trade policy in Stage II reduces the food price and thereby improves the living standards of the masses. The resulting widespread investment enables a departure from stagnation in which a large part of labor is required for food production. Such free-trade trade policy is supported by the landed class, who have a relatively weak incentive to protect agriculture due to their small gains from landownership.

In Country B, by contrast, land rents are the major source of landowners' incomes and a substantial amount of capital is necessary for them to support a pro-industrial, anti-agricultural policy. Hence, large-size landlords will stick to agricultural protection. Such an anti-industrial policy impedes the food-price reduction and thereby discourages productive activities by the mass. The economy will accordingly stagnate in underdeveloped stages. ${ }^{52}$

\section{Concluding Remarks}

This article has developed a theoretical framework for understanding the evolution of trade policy, underlying internal class conflicts, and global income divergence over the last few centuries. It analyzes the dynamic interaction between trade policy and economic development, and thereby bridges a gap between two strands of literature - open-economy growth theories and endogenous tariff theories. On the one hand, trade-policy preferences and the executed trade policy depend on the stage of development. Due to the distributional effects of trade liberalization, income sources as well as income levels characterize individuals' attitudes towards trade policy, and these two elements vary in the process of development. On the other hand, engaging in international trade affects aggregate output, income distribution and private investment through specialization in a sector with a comparative advantage. The central argument of this paper is that this mutual dependence between trade policy and development has been one of the principal forces operating behind the evolution of the world economy, particularly since the mid-19th century, when European

\footnotetext{
${ }^{52}$ If $X$ is excessively large, the economy will converge to a steady-state equilibrium where it has a comparative advantage in agriculture. This paper does not go into this case, though.
} 
trade liberalization launched. The latter part of this paper has shown that the path of economic development in part depends on the relative size of land in landowners' portfolios.

A large portion of the article dwells on 19th-century Western Europe, which had a comparative advantage in manufacturing in global markets and pulled ahead of the other nations by trade expansion. Consistent with this historical experience, the proposed theory argues that capitalabundant, land-scarce (i.e., Western European) economies undergo a non-monotonic evolution of trade policy in the growth process.

The first wave of liberalism is triggered by a shift in landlords' stance towards liberalism, a shift associated with the increasing importance of industrial capital in their portfolios. Specialization in manufacturing after trade liberalization fuels aggregate output by releasing the economy from resource constraints. In addition, the landless poor benefit from trade which provides them with inexpensive staple food.

The subsequent political backlash results from improved living standards and the accompanying political participation of the middle class, who care about the purchasing power of capital-intensive goods as well as that of land-intensive goods. The retreat into protectionism is, however, not a universal phenomenon and a bifurcation of trade policy is observed in this intermediate development stage. It is demonstrated that the political backlash will occur in moderately land-scarce countries with, such as France and Germany, but not in severely land-scarce countries, such as Great Britain. On top of that, the surge of protectionism will not bring the economy back to previous stages as long as the amount of land is relatively small. These asymmetric results regarding trade protection apply to the case of Western Europe in the late 19th century.

Further specialization in manufacturing in later stages shrinks domestic agriculture and accordingly all individuals, regardless of their landownership, are inclined to support pro-industrial, liberal policies. The developed theory therefore predicts the dissipation of class conflicts over trade policy. Land-scarce countries accordingly reach a developed stage with free trade despite the possibility of their temporary retreat to protectionism.

Contrary to the above-mentioned scenario, countries with large-scale landlords are likely to remain protectionist - an outcome that leads to global income divergence. The relative importance of land is typically dominant in their portfolios, and in order to secure this principal income source, those landed interests have a strong incentive to oppose a pro-industrial policy. Such negative 
attitudes towards industrialization prevent improvements in working-class living standards, and in this circumstances, the masses need to spend most of their incomes on the consumption of staple foods, leaving no resources for productive activities.

While this article has taken a novel approach to analyzing the potential relationship between trade policy and economic development, it omits several aspects relevant to the world economy during the period under consideration. First, the developed model abstracts from technological progress, in particular improvements in transportation productivity, which has promoted the integration of global markets. Second, the paper has confined its assessment to the direct, quantitative impacts of trade in commodities on trading economies. As argued by Irwin $(2001,3)$, however, one should also pay attention to several Asian commodities that were traded in small quantities, as they may have conveyed embodied new technology to Europe. Third, it will be desirable to consider political games between trading countries who strategically adopt their trade policies. Altering the small-open economy assumption enables to take into account the home country's reaction to foreign countries' trade policies. Finally, this paper has considered the economy producing a single manufactured good, and hence unable to analyze the protection for manufacturing sectors. Although its focus on agricultural protection is a reasonable simplification to study European trade policy before the 20th century, it would be less appropriate for contemporary debates; nowadays the protection of domestic industry would have greater impacts on advanced economies than that of agricultural goods would. Future research should be directed to addressing these issues.

\section{Appendix}

\section{Patterns of Specialization}

If the production of the manufactured good takes place at time $t+1$, both numerator and denominator of $q(\cdot)$ must be positive. To check this condition, first define a level of $k_{t+1}, k_{t+1}^{d}$, for which the denominator of $q(\cdot)$ is zero. Then, $\forall\left(b_{t}^{P}, p_{t+1}, \theta_{t}\right) \in \mathbb{R}_{+} \times \mathbb{R}_{++} \times(0,1]$,

$$
\theta_{t} h\left(e\left(k_{t+1}\right)\right)+\left(1-\theta_{t}\right) h\left(b_{t}^{P}\right)-H^{A}\left(k_{t+1}, p_{t+1}\right) \begin{cases}<0 & \text { for } k_{t+1} \in\left(0, k_{t+1}^{d}\right), \\ =0 & \text { for } k_{t+1}=k_{t+1}^{d} \\ >0 & \text { for } k_{t+1}>k_{t+1}^{d} .\end{cases}
$$

The existence of $k_{t+1}^{d}$ is guaranteed by the properties of $H^{A}(\cdot)$. It follows that $k_{t+1}^{d}=k^{d}\left(b_{t}^{P}, p_{t+1}, \theta_{t}\right)>$ 0 with $k_{p}^{d}(\cdot)>0$. Second, let $k_{t+1}^{n}$ be a value of $k_{t+1}$ for which the numerator of $q(\cdot)$ is zero. Then 
for a given $B_{t}>0$,

$$
B_{t}-\theta_{t} e\left(k_{t+1}\right)-\left(1-\theta_{t}\right) b_{t}^{P} \begin{cases}>0 & \text { for } k_{t+1} \in\left(0, k_{t+1}^{n}\right) \\ =0 & \text { for } k_{t+1}=k_{t+1}^{n} \\ <0 & \text { for } k_{t+1}>k_{t+1}^{n}\end{cases}
$$

It follows from $e^{\prime}\left(k_{t+1}\right)>0$ that $k_{t+1}^{n}=k^{n}\left(B_{t}, b_{t}^{P}, \theta_{t}\right)$.

Given these results, one can define $p_{t+1}^{\max }$, the upper bound of the price for incomplete specialization, to satisfy

$$
k^{d}\left(b_{t}^{P}, p_{t+1}^{\max }, \theta_{t}\right)=k^{n}\left(B_{t}, b_{t}^{P}, \theta_{t}\right)
$$

where $\left(B_{t}, b_{t}^{P}, \theta_{t}\right) \in \mathbb{R}_{++} \times \mathbb{R}_{+} \times(0,1]$. This relationship yields a single-valued function $p_{t+1}^{\max }=$ $p^{\max }\left(B_{t}, b_{t}^{P}, \theta_{t}\right)$ on the set. The patterns of specialization depend on the relationship between $p_{t+1}$ and $p_{t+1}^{\max }$. Consider the following two possible cases for a given triplet $\left(B_{t}, b_{t}^{P}, \theta_{t}\right)$ on the domain above.

Case I: $0<p_{t+1}<p_{t+1}^{\max }$. Recalling $\partial k_{t+1}^{d} / \partial p_{t+1}>0$ and (67), one can find $0<k_{t+1}^{d}<k_{t+1}^{n}$. As follows from (65) and (66) that, for $k_{t+1} \in\left(k_{t+1}^{d}, k_{t+1}^{n}\right)$, (i) both numerator and denominator of $q(\cdot)$ are positive, and (ii) $q(\cdot)$ is decreasing in $k_{t+1}$. On the other hand, $q(\cdot)<0$ for $k_{t+1} \in$ $\mathbb{R}_{++} \backslash\left[k_{t+1}^{d}, k_{t+1}^{n}\right]$. These properties guarantee the existence of a unique value $k_{t+1} \in\left(k_{t+1}^{d}, k_{t+1}^{n}\right)$ satisfying (23). Members of group $R$ are not credit-constrained in period $t$.

Case II: $p_{t+1}^{\max } \leq p_{t+1}$. It follows that $0<k_{t+1}^{n} \leq k_{t+1}^{d}$, implying that $q\left(k_{t+1} ; \cdot\right)<0$ for $k_{t+1} \in \mathbb{R}_{++} \backslash\left[k_{t+1}^{d}, k_{t+1}^{n}\right]$, and both numerator and denominator of $q(\cdot)$ are non-positive for $k_{t+1} \in$ $\left[k_{t+1}^{d}, k_{t+1}^{n}\right]$. In this case $y_{t+1}^{M}=0$ since physical and human capital are indisputable to generate the manufacturing good. The economy will fully specialize in agriculture. As a result, individuals with perfect foresight do not save and spend all their bequests on education.

\section{Proof of Lemma 1}

Suppose $H_{t}^{A}=H_{0}^{A}$. Then $H_{t}^{M}=H_{t}-H_{0}^{A}>0$ and thus (23) yields $k_{t}>0$. Also, one can use (7) and (19) to get $I_{t}^{P}=w_{t}=p_{t} F_{H}\left(X, H_{0}^{A}\right)$. Hence, in view of (29) and (31), $H_{t}^{A}=H_{0}^{A}$ and $p_{t}=w\left(k_{t}\right) / F_{H}\left(X, H_{0}^{A}\right)$ satisfy $(28)$ and $I_{t}^{P}<p_{t} \hat{c}<I_{t}^{R}$ holds in the equilibrium.

Recalling Corollary 1, the uniqueness of $H_{0}^{A}$ is verified if neither $(a) p_{t} \hat{c} \leq I_{t}^{P} \leq I_{t}^{R}$ nor $(b)$ $I_{t}^{P} \leq I_{t}^{R} \leq p_{t} \hat{c}$ occurs in other equilibria. Case $(a)$ implies $\hat{c} \leq F_{H}\left(X, H_{t}^{A}\right)$. It then follows from (29) that $H_{t}^{A}<H_{0}^{A}$ and $y_{t}^{A}<\hat{c}$, which violates (28). In case (b), (10) and (13) yield $c_{t}^{R} \leq \hat{c}$ and 
$B_{t}=0$, thus $H_{t}^{A}=H_{t}>H_{0}^{A}$. Noting (31), this leads to $c_{t}^{R}=\left[F\left(X, H_{t}\right)-(1-\lambda) F_{H}\left(X, H_{t}\right)\right] / \lambda>\hat{c}$, a contradiction.

\section{The Wage Elasticity}

$$
\gamma_{t}=\frac{D_{t}}{D_{t}+H_{t}^{M}+\frac{\theta_{t-1}}{1-\alpha} e^{\prime}\left(k_{t}\right)}
$$

where

$$
D_{t} \equiv \frac{-\alpha F_{H}\left(X, H_{t}^{A}\right)}{F_{H H}\left(X, H_{t}^{A}\right)}=\frac{\alpha H_{t}^{A}\left[a+(1-a)\left(X / H_{t}^{A}\right)^{-\rho}\right]}{a(1-\rho)} .
$$

\section{Proof of Lemma 3}

Noting (8), (24), (38) and (39), one can find that the first and second brackets in (40) respectively increase and decrease with $B_{t}$. Hence, in light of (41), the lemma is proven by showing that $v_{t}^{R, w}>$ $v_{t}^{R, c}$ for a sufficiently large value of $B_{t}$. Using $w_{t}^{M}=-(1-\alpha) y_{t}^{M} / H_{t}^{M}$, one can find that

$$
y_{t}^{M, w}-(1-\lambda) w_{t}^{M, w}=\left[\alpha+(1-\alpha) \frac{H_{t}^{M}-(1-\lambda)}{H_{t}^{M}}\right] y_{t}^{M, w} \equiv \pi_{t} y_{t}^{M, w} \text {, }
$$

where $\pi_{t+1}$ approaches 1 as $B_{t}$ goes to infinity, noting the properties of $h\left(e_{t}\right)$. Thus,

$$
\lim _{B_{t} \rightarrow 0}\left(\pi_{t+1} y_{t+1}^{M, w}-y_{t+1}^{M, c}\right)=\lim _{B_{t} \rightarrow 0}\left(y_{t+1}^{M, w}-y_{t+1}^{M, c}\right) .
$$

Since (38) and (39) imply the strict concavity of $y_{t+1}^{M}$ with respect to $H_{t+1}^{A}$,

$$
y_{t+1}^{M, w}-y_{t+1}^{M, c}>w_{t+1}^{M, w}\left(H_{0}^{A}-H_{t+1}^{A, w}\right)
$$

where the right-hand side becomes infinitely large as $B_{t}$ goes to infinity. It thus follows from (40) that $v_{t}^{R, w}>v_{t}^{R, c}$ for a sufficiently large value of $B_{t}$.

\section{Proof of Lemma 4}

As follows from (13) and (19), the evolution of $b_{t}^{P}$ conditional on $k_{t+1}=k$ is

$$
b_{t+1}^{P}=\beta \max \left[I\left(b_{t}^{P} ; k\right)-p^{w} \hat{c}, 0\right] \equiv \varphi\left(b_{t}^{P} ; k\right),
$$

where

$$
I\left(b_{t}^{P} ; k\right) \equiv \begin{cases}w(k) h\left(b_{t}^{P}\right) & \text { for } b_{t}^{P}<e(k) \\ w(k) h(e(k))+R(k)\left[b_{t}^{P}-e(k)\right] & \text { for } b_{t}^{P} \geq e(k) .\end{cases}
$$


Noting $w(\hat{k})=p^{w} \hat{c}$ and $\beta R(\hat{k})>1$ from $(\mathrm{A} 4)$,

$$
0=\varphi(0 ; \hat{k}) \quad \text { and } \quad \varphi_{b}\left(b_{t}^{P} ; \hat{k}\right)>1, \forall b_{t}^{P}>0
$$

Therefore, this first-order difference equation has no steady state if $k>\hat{k}$ and $R(k)>1$, otherwise it has a unique steady-state.

In addition, one can find

$$
\begin{aligned}
& \varphi_{k}\left(b_{t}^{P} ; k\right)>0 \text { for } b_{t}^{P}<e(k) \\
& \varphi_{k}\left(b_{t}^{P} ; k\right)<0 \text { for } b_{t}^{P} \geq \bar{b}^{P} \text { and } k \leq \bar{k},
\end{aligned}
$$

noting $H^{A}\left(\bar{k}, p^{w}\right)=0$ and $\bar{b}^{P}=\bar{B}>\max [e(\bar{k}), \bar{k}]$ with

$$
I_{k}\left(b_{t}^{P}, k\right)= \begin{cases}w^{\prime}(k) h\left(b_{t}^{P}\right) & \text { for } b_{t}^{P}<e(k) \\ (1-\alpha) R(k)\left[h(e(k))-b_{t}^{P} / k\right] & \text { for } b_{t}^{P} \geq e(k)\end{cases}
$$

The results above characterize the relationship between $b_{t}^{P}$ and $k$ implied by $b_{t}^{P}=\varphi\left(b_{t}^{P} ; k\right)$. By noting (24) and (A3), one can map this relationship onto the $b b$ locus on the $\left(B_{t}, b_{t}^{P}\right)$ space to establish the result.

\section{References}

Allen, Robert C., "The Great Divergence in European Wages and Prices from the Middle Ages to the First World War," Explorations in Economic History, 2001, 38, 411-447.

Aydelotte, W. O., "The Country Gentlemen and the Repeal of the Corn Laws," English Historical Review, January 1967, 82 (322), 47-60.

Bairoch, Paul, "European Trade Policy, 1815-1914," in Peter Mathias and Sidney Pollard, eds., The Cambridge Economic History of Europe, Vol. VIII, Cambridge: Cambridge University Press, 1989, pp. 1-160.

Baldwin, Richard E., Philippe Martin, and Gianmarco I. P. Ottaviano, "Global Income Divergence, Trade, and Industrialization: The Geography of Growth Take-Offs," Journal of Economic Growth, March 2001, $6,5-37$.

Banerjee, Abhijit V. and Andrew Newman, "Occupational Choice and the Process of Development," Journal of Political Economy, 1993, 101 (2), 274-298.

Barnes, Donald Grove, A History of the English Corn Laws, New York: Augustus M. Kelley, 1965.

Ben-David, Dan and Michael B. Loewy, "Free Trade, Growth, and Convergence," Journal of Economic Growth, June 1998, 3, 143-170.

Benabou, Roland, "Inequality and Growth," in Ben S. Bernanke and Julio J. Rotemberg, eds., NBER Macroeconomics Annual 1996, Cambridge, MA: MIT Press, 1996, pp. 11-74.

Blattman, Christopher, Jason Hwang, and Jeffrey G. Williamson, "The Terms of Trade and Economic Growth in the Periphery 1870-1983," Working Paper 9940, National Bureau of Economic Research, Cambridge, MA 2003. 
Coppel, J. and M. Durand, "Trends in Market Openness," Working Paper 221, OECD Economics Department, Paris 1999.

Findlay, Ronald and Kevin H. O'Rourke, "Commodity Market Integration, 1500-2000," Working Paper 8579, National Bureau of Economic Research, Cambridge, MA November 2001.

Flora, Peter, Jens Alber, and Franz Kraus, State, Economy, and Society in Western Europe 1815-1975, Vol. I, Frankfurt: Campus Verlag, 1983.

Flug, Karnit, Antonio Spilimbergo, and Erik Wachtenheim, "Investment in Education: Do Economic Volatility and Credit Constraints Matter?," Journal of Development Economics, 1998, 55, 465-481.

Galor, Oded and Andrew Mountford, "Trade, Demographic Transition, and the Great Divergence: Why are a Third of People Indian or Chinese?," Mimeo, January 2003.

and David N. Weil, "Population, Technology, and Growth: From Malthusian Stagnation to the Demographic Transition and Beyond," American Economic Review, September 2000, 90 (4), 806-828.

and Joseph Zeira, "Income Distribution and Macroeconomics," Review of Economic Studies, January 1993, $60(1), 35-52$.

and Omer Moav, "From Physical to Human Capital Accumulation: Inequality and the Process of Development," Review of Economic Studies, October 2004, 71 (4), 1001-1026.

_, , and Dietrich Vollrath, "Divergence and Overtaking: Land Abundance as a Hurdle for Education Reforms," Mimeo, August 2002.

Glamann, Kristof, "European Trade 1500-1750," in Carlo M. Cipolla, ed., The Fontana Economic History of Europe: The Sixteenth and Seventeenth Centuries, London: Collins/Fontana, 1974, chapter 6, pp. 427526 .

Goodfriend, Marvin and John McDermott, "Early Development," American Economic Review, March 1995, $85(1), 116-33$.

Grossman, Gene M. and Elhanan Helpman, "Protection for Sale," American Economic Review, September 1994, 84 (4), 866-850.

Hansen, Gary D. and Edward C. Prescott, "Malthus to Solow," American Economic Review, September 2002, 92 (4), 1205-17.

Hoffman, Phillip T., David S. Jacks, Patricia A. Levin, and Peter H. Lindert, "Real Inequality in Europe Since 1500," Journal of Economic History, June 2002, 62 (2), 322-355.

Irwin, Douglas A., "Welfare Effects of British Free Trade: Devate and Evidence from the 1840s," Journal of Political Economy, December 1988, 96, 1142-1164.

_ - "Political Ecnomy and Peel's Repeal of the Corn Laws," Economics and Politics, Spring 1989, 1, $41-59$.

_ - "Comments on Ronald Findlay and Kevin O'Rourke," in "Globalization in Historical Perspective," The University of Chicago Press, 2001.

Jones, E. L., The European Miracle: Environments, Economies and Geopolitics in the History of Europe and Asia, second ed., Cambridge: Cambridge University Press, 1981.

Kindleberger, Charles P., "Group Behavior and Internatinal Trade," Journal of Political Economy, February 1951, 59 (1), 30-46.

_ - "The Rise of Free Trade in Western Europe, 1820-1875," Journal of Economic History, March 1975, $35(1), 20-55$.

Kogel, Tomas and Alexia Prskawetz, "Agricultural Productivity Growth and Escape from the Malthusian Trap," Journal of Economic Growth, 2001, 6, 337-357. 
Kohn, Meir, "The Expansion of Trade and the Transformation of Agriculture in Pre-Industrial Europe," in "The Origins of Western Economic Success: Commerce, Finance, and Government in Pre-Industrial Europe" 2001a.

, "Trading Costs and the Pattern of Trade in Pre-Industrial Europe," in "The Origins of Western Economic Success: Commerce, Finance, and Government in Pre-Industrial Europe" $2001 \mathrm{~b}$.

Kriedte, Peter, Peasants, Landlords and Merchant Capitalists, Leamington Spa, Warwickshire: Berg Publishers Ltd., 1983.

Lamartine Yates, Paul, Forty Years of Foreign Trade, New York: Macmillan, 1959.

Leontief, Wassily W., "Domestic Production and Foreign Trade: The American Capital Position ReExamined," Proceedings of the American Philosophical Society, September 1953, 97 (4), 332-349.

Lindert, Peter H. and Jeffrey G. Williamson, "Does Globalization Make the World More Unequal?," Mimeo, May 2001.

Maddison, Angus, The World Economy: A Millennial Perspective, Paris: the OECD Development Centre, 2001.

Magee, Stephen P., William A. Brock, and Leslie Young, Black Hole Tariffs and Endogenous Policy Theory, Cambridge: Cambridge University Press, 1989.

Mayer, Wolfgang, "Endogenous Tariff Formation," American Economic Review, December 1984, 74 (5), 970-985.

McDermott, John, "Mercantilism and Modern Growth," Journal of Economic Growth, March 1999, 4, 55-80. , "Development Dynamics: Economic Integration and the Demographic Transition," Journal of Economic Growth, 2002, 7, 371-409.

Minchinton, Walter, "Patterns of Demand 1750-1914," in Carlo M. Cipolla, ed., The Fontana Economic History of Europe: The Industrial Revolution, London: Collins/Fontana, 1973, chapter 2, pp. 77-186.

_ "Patterns and Structure of Demand 1500-1750," in Carlo M. Cipolla, ed., The Fontana Economic History of Europe: The Sixteenth and Seventeenth Centuries, London: Collins/Fontana, 1974, chapter 2, pp. $83-176$.

Nash, R. C., "South Carolina and the Atlantic Economy in the Late Seventeenth and Eighteenth Centuries," Economic History Review, November 1992, 45 (4), 677-702.

Ormrod, David, The Rise of Commercial Empires: England and the Netherlands in the Age of Mercantilism, 1650-1770, Cambridge, UK: Cambridge University Press, 2003.

O’Rourke, Kevin H., "The European Grain Invasion, 1870-1913," Journal of Economic History, 4 1997, 57, 775-801.

, "British Trade Policy in the 19th Century: A Review Article," European Journal of Political Economy, 2000, 16, 829-842.

, "Globalization and Inequality: Historical Trends," Working Paper 8339, National Bureau of Economic Research, Cambridge, MA June 2001.

, Alan M. Taylor, and Jeffrey G. Williamson, "Factor Price Converegence in the Late Nineteenth Century," International Economic Review, August 1996, 37 (3), 499-530.

and Jeffrey G. Williamson, Globalization and History, Cambridge, MA: The MIT Press, 1999.

and __ "When Did Globalization Begin?," Working Paper 7632, National Bureau of Economic Research, Cambridge, MA April 2000.

and __ "After Columbus: Explaining the Global Trade Boom 1500-1800," Working Paper 8186, National Bureau of Economic Research, Cambridge, MA March 2001. 
_ _ and _ _ , "From Malthus to Ohlin: Trade, Growth and Distribution Since 1500," Mimeo, February 2003.

Pomeranz, Kenneth, The Great Divergence, Princeton, NJ: Princeton University Press, 2000.

Rogowski, Ronald, Commerce and Coalitions: How Trade Affects Domestic Political Arrangements, Princeton, NJ: Princeton University Press, 1989.

Sachs, J. D. and A. Warner, "Economic Reform and the Process Fof Global Integration," in "Brookings Papers on Economic Activity," Vol. I, Washington, D.C.: Brookings Institution, 1995.

Scheve, Kenneth F. and Matthew J. Slaughter, "What Determines Individual Trade-Policy Preferences?," Journal of International Economics, 2001, 54, 267-292.

Schonhardt-Bailey, Cheryl, "Specific Factors, Capital Markets, Portfolio Diversification, and Free Trade: Domestic Determinants of the Repeal of the Corn Laws," World Politics, July 1991, 43 (4), 545-569.

Taylor, Alan M., "Globalization, Trade, and Development: Some Lessons From History," Working Paper 9326, National Bureau of Economic Research, Cambridge, MA November 2002.

Thompson, F. M. L., "Business and Landed Elites in the Nineteenth Century," in F. M. L. Thompson, ed., Landowners, Capitalists, and Entrepreneurs: Essays for Sir John Habakkuk, New York: Oxford University Press, 1994, chapter 5, pp. 139-170.

Trefler, Daniel, "The Case of the Missing Trade and Other Mysteries," American Economic Review, December 1995, 85 (5), 1029-1046.

Vries, Jan De, Economy of Europe in an Age of Crisis 1600-1750, Cambridge, UK: Cambridge University Press, 1976.

Webb, Walter Prescott, The Great Frontier, Austin, Texas: University of Texas Press, 1952.

Williamson, Jeffrey G., "The Impact of the Corn Laws Just Prior to Repeal," Explorations in Economic History, 1990, 27, 123-156.

, "Is Protection Bad for Growth? Will Globalization Last? Looking for Answers in History," Mimeo, 2002a.

_ "Land, Labor, and Globalization in the Third World, 1870-1940," Journal of Economic History, March 2002b, 62 (1), 55-85.

, "Winners and Losers over Two Centuries of Globalization," Working Paper 9161, National Bureau of Economic Research, Cambridge, MA September 2002c.

__ , "Stolper-Samuelson, Strategic Tariffs and Revenue Needs: World Tariffs 1789-1938," Mimeo, June 2003.

Woodruff, William, "The Emergence of an International Economy," in Carlo M. Cipolla, ed., The Fontana Economic History of Europe: The Emergence of Industrial Societies-2, Vol. 4(2), London: Collins/Fontana, 1973, chapter 11, pp. 656-737. 
Endogenous Globalization and Income Divergence

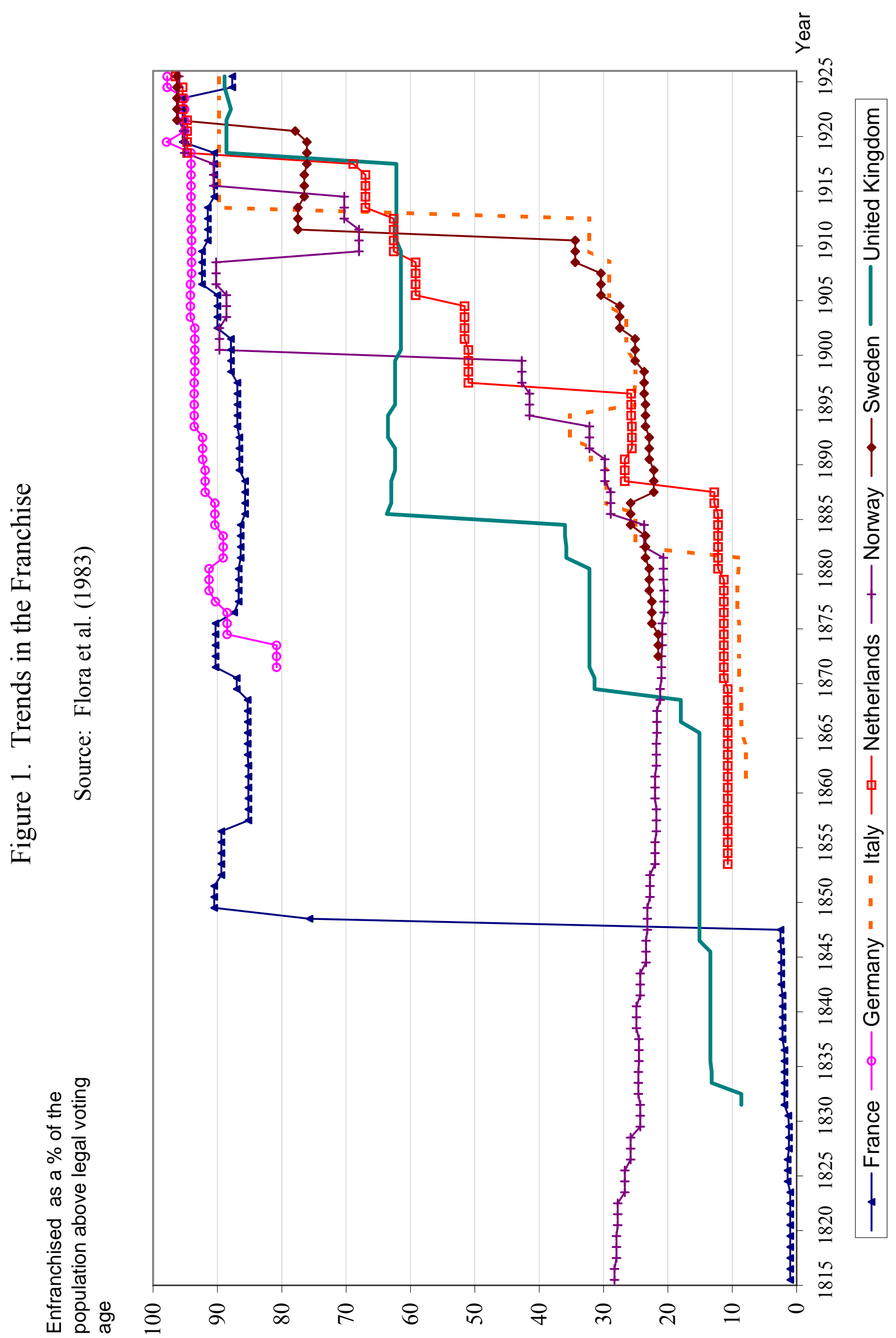


Yoshaki Sugimoto

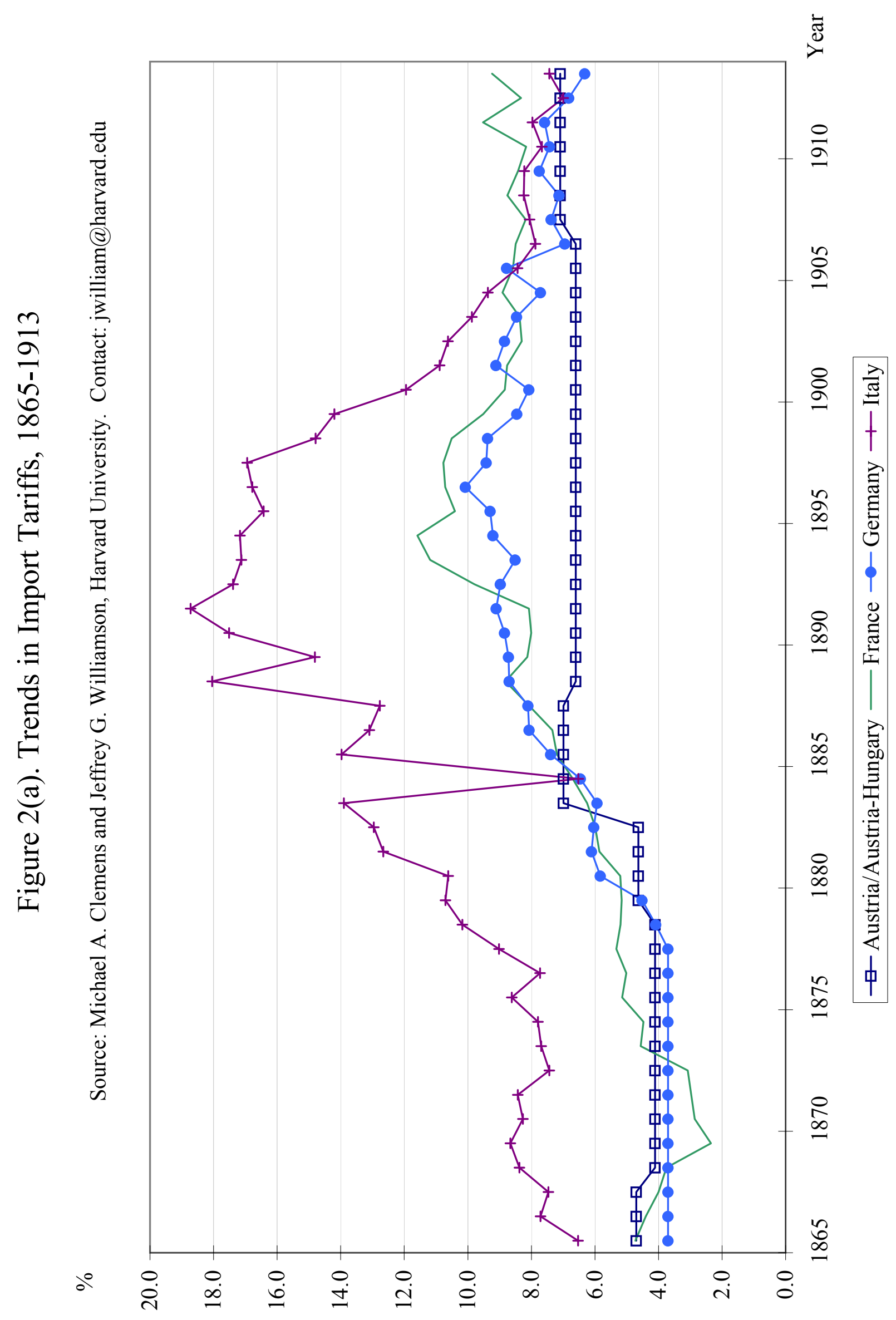

EUI WP ECO 2005/3 
Endogenous Globalization and Income Divergence

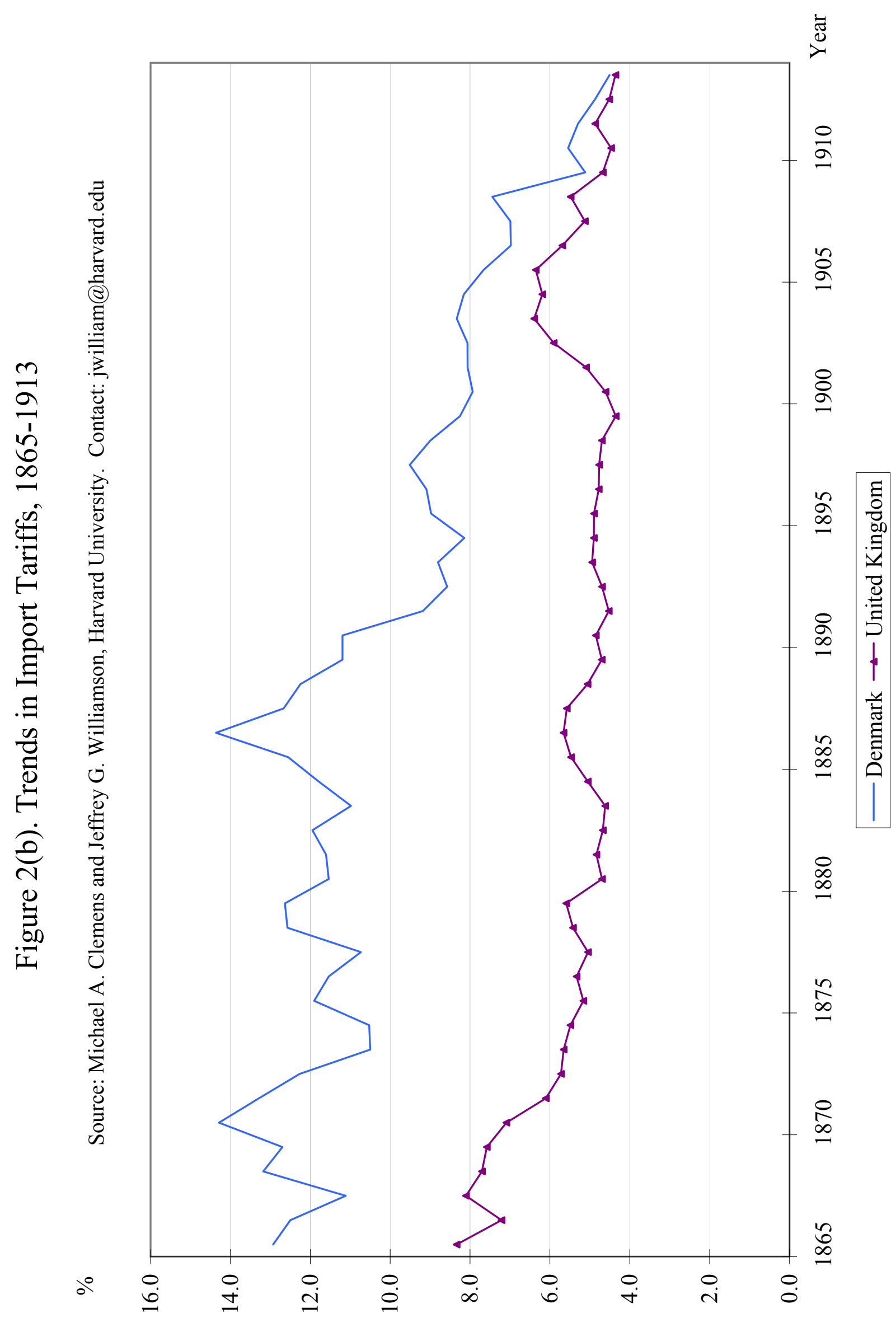




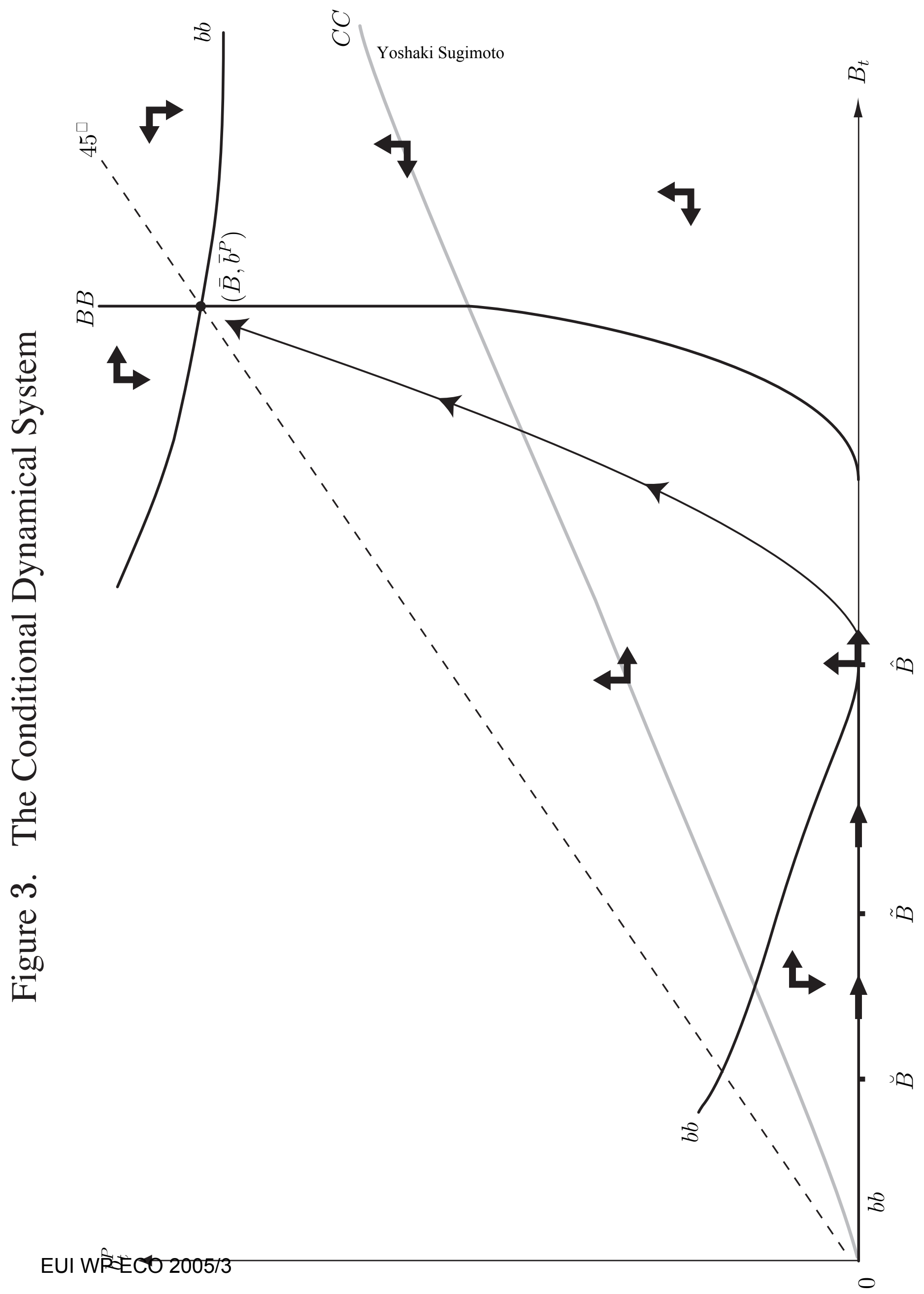




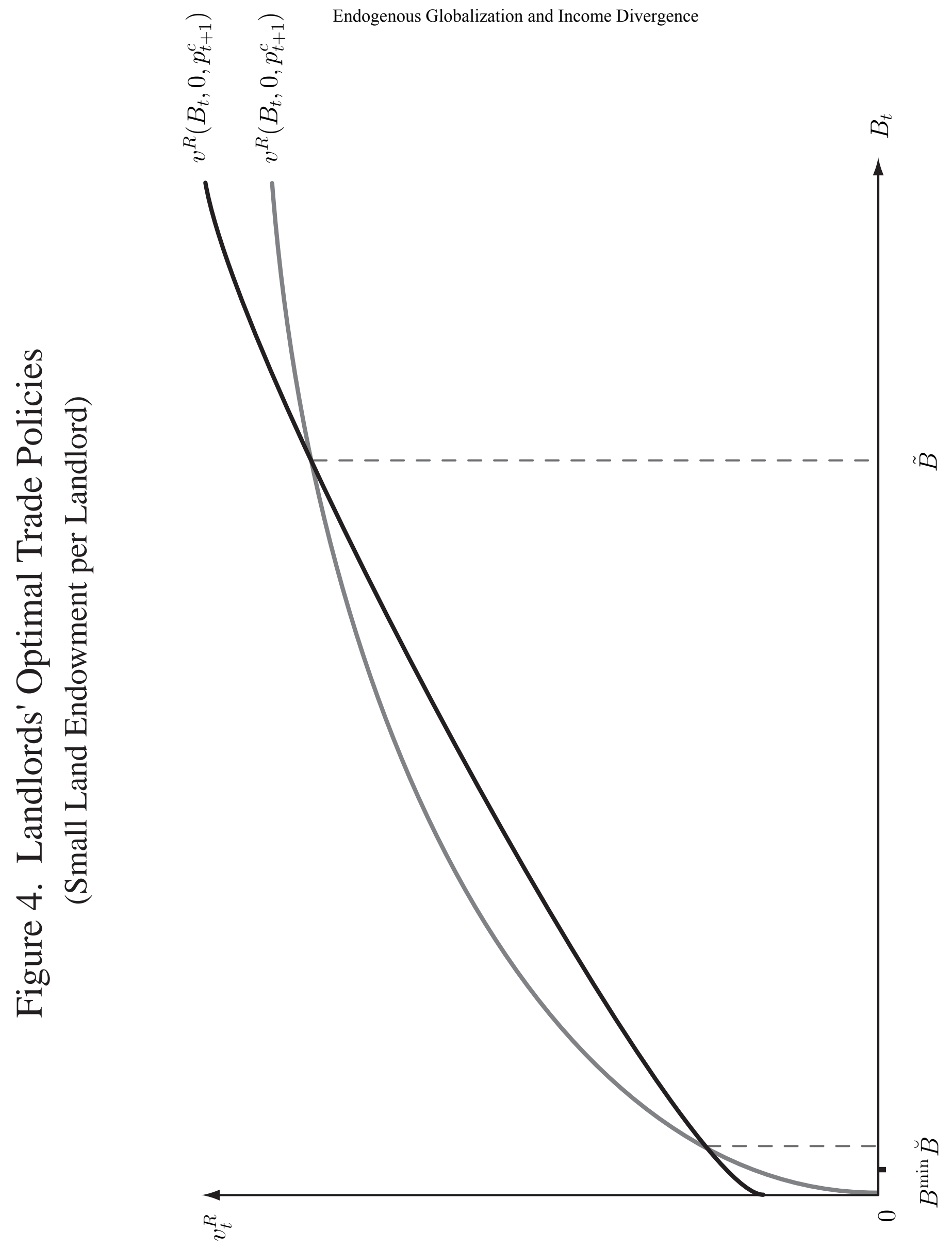

